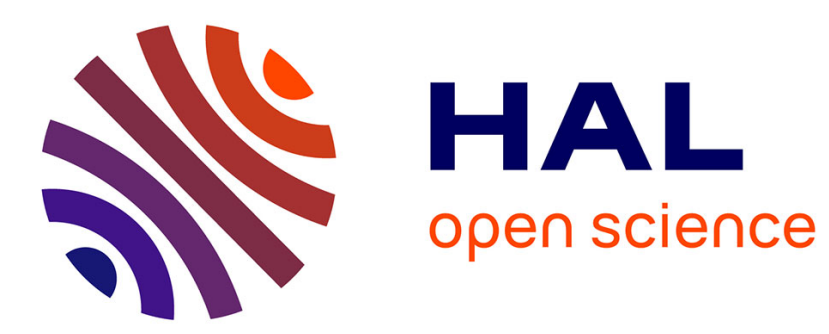

\title{
Self-organized kilometer-scale shoreline sand wave generation: Sensitivity to model and physical parameters
}

Déborah Idier, Albert Falqués, Jeremy Rohmer, Jaime Arriaga

\section{To cite this version:}

Déborah Idier, Albert Falqués, Jeremy Rohmer, Jaime Arriaga. Self-organized kilometer-scale shoreline sand wave generation: Sensitivity to model and physical parameters. Journal of Geophysical Research : Solid Earth, 2017, 122, 10.1002/2017JF004197 . hal-01590706

\section{HAL Id: hal-01590706 https: / hal-brgm.archives-ouvertes.fr/hal-01590706}

Submitted on 20 Sep 2017

HAL is a multi-disciplinary open access archive for the deposit and dissemination of scientific research documents, whether they are published or not. The documents may come from teaching and research institutions in France or abroad, or from public or private research centers.
L'archive ouverte pluridisciplinaire HAL, est destinée au dépôt et à la diffusion de documents scientifiques de niveau recherche, publiés ou non, émanant des établissements d'enseignement et de recherche français ou étrangers, des laboratoires publics ou privés. 
Journal of Geophysical Research: Earth Surface

\author{
RESEARCH ARTICLE \\ 10.1002/2017JF004197 \\ Key Points: \\ - The critical wave angle for shoreline \\ sand wave formation is highly \\ sensitive to the bathymetry \\ - Sand waves under low-angle \\ waves are favored by bathymetric \\ undulations more pronounced than \\ the shoreline undulations \\ - Large wave angle, large closure depth, \\ and small wave period favor shoreline \\ sand wave formation
}

Supporting Information:

- Supporting Information S1

Correspondence to:

D. Idier,

d.idier@brgm.fr

Citation:

Idier, D., A. Falqués, J. Rohmer, and

J. Arriaga (2017), Self-organized

kilometer-scale shoreline sand

wave generation: Sensitivity to

model and physical parameters,

J. Geophys. Res. Earth Surf., 122,

doi:10.1002/2017JF004197.

Received 2 JAN 2017

Accepted 30 JUL 2017

Accepted article online 11 AUG 2017

(2)2017. American Geophysical Union. All Rights Reserved.

\section{Self-organized kilometer-scale shoreline sand wave generation: Sensitivity to model and physical parameters}

\author{
Déborah Idier ${ }^{1}$ iD , Albert Falqués ${ }^{2}$, Jérémy Rohmer ${ }^{1}$, and Jaime Arriaga ${ }^{2}$ \\ ${ }^{1}$ BRGM, Orléans, France, ${ }^{2}$ Department of Applied Physics, Universitat Politècnica de Catalunya, Barcelona, Spain
}

\begin{abstract}
The instability mechanisms for self-organized kilometer-scale shoreline sand waves have been extensively explored by modeling. However, while the assumed bathymetric perturbation associated with the sand wave controls the feedback between morphology and waves, its effect on the instability onset has not been explored. In addition, no systematic investigation of the effect of the physical parameters has been done yet. Using a linear stability model, we investigate the effect of wave conditions, cross-shore profile, closure depth, and two perturbation shapes (P1: cross-shore bathymetric profile shift, and P2: bed level perturbation linearly decreasing offshore). For a P1 perturbation, no instability occurs below an absolute critical angle $\theta_{c 0} \approx 40-50^{\circ}$. For a P2 perturbation, there is no absolute critical angle: sand waves can develop also for low-angle waves. In fact, the bathymetric perturbation shape plays a key role in low-angle wave instability: such instability only develops if the curvature of the depth contours offshore the breaking zone is larger than the shoreline one. This can occur for the P2 perturbation but not for P1. The analysis of bathymetric data suggests that both curvature configurations could exist in nature. For both perturbation types, large wave angle, small wave period, and large closure depth strongly favor instability. The cross-shore profile has almost no effect with a P1 perturbation, whereas large surf zone slope and gently sloping shoreface strongly enhance instability under low-angle waves for a P2 perturbation. Finally, predictive statistical models are set up to identify sites prone to exhibit either a critical angle close to $\theta_{c 0}$ or low-angle wave instability.
\end{abstract}

\section{Introduction}

Sandy shorelines often exhibit alongshore undulations at different length scales. Well-known examples are beach cusps (typical alongshore wavelength, $L \sim 1-50 \mathrm{~m}$ ) and megacusps (typically $L \sim 100-1000 \mathrm{~m}$ ), which are associated with swash zone processes and with surf zone rhythmic bars, respectively [Ribas et al., 2015]. However, there are larger-scale shoreline undulations with $L \sim 1-10 \mathrm{~km}$ that are not directly linked to surf zone rhythmic bars but to similar undulations in the bathymetric contours up to a certain depth in the shoaling zone [Ruessink and Jeuken, 2002; Davidson-Arnott and van Heyningen, 2003; Medellín et al., 2008; Ryabchuk et al., 2011; Kaergaard et al., 2012; Idier and Falqués, 2014]. We will call them kilometer-scale shoreline sand waves or simply shoreline sand waves. Some of these submarine geomorphic features can be forced by offshore bathymetric anomalies or by antecedent geological constraints [Riggs et al., 1995; Bender and Dean, 2003; Valvo et al., 2006]. Others, suspected to result from self-organization processes, exhibit an alongshore migration. This migration is sometimes visually obvious [see, e.g., Davidson-Arnott and van Heyningen, 2003; Kaergaard et al., 2012] or is suggested by the observation of migrating zones of erosion and accretion [see, e.g., Ruessink and Jeuken, 2002]. Here we focus on self-organized shoreline sand waves.

The self-organized origin of coastal morphological patterns is widely accepted in case of beach cusps and rhythmic surf zone bars [see, e.g., Coco and Murray, 2007; Ribas et al., 2015]. In case of shoreline sand waves, it has been hypothesized that they could emerge from a feedback between the morphology and the wave field involving (i) the wave-driven longshore sediment transport and (ii) the cross-shore sediment exchange between the surf and shoaling zones that is responsible for the cross-shore equilibrium profile. This feedback mechanism was proposed by Ashton et al. [2001] and later confirmed and refined in a number of modeling studies [Falqués and Calvete, 2005; Ashton and Murray, 2006a; van den Berg et al., 2012; Kaergaard and Fredsoe, 2013a]. These studies show that sand waves develop for (deep water) wave angle with respect to shore normal 
larger than a certain threshold, $\theta_{c}$, with $\theta_{c} \geq \theta_{c 0}$ and $\theta_{c 0} \sim 42^{\circ}$. In the present paper, $\theta_{c}$ will be called the critical wave angle and $\theta_{c 0}$ the absolute critical wangle. However, Idier et al. [2011] found that for particular bathymetric profiles and wave conditions this positive feedback could also occur for low wave angles. These instabilities have been called high-angle wave instability (HAWI) and low-angle wave instability (LAWI), respectively.

These modeling studies have extensively explored the basic instability mechanism, how it depends on the wave angle, and its consequences on sand wave formation. Some of them have investigated the effect of wave height, wave period, bathymetric profile, and closure depth on the growth rate (when there was instability) or wavelength of shoreline instabilities. For instance, after Ashton and Murray [2006b], an increase of wave height $H$ and period $T$ leads to an increase of the diffusional time scale $\left(\propto H^{12 / 5} T^{1 / 5}\right)$, i.e., speeds up the sand waves development in case of high-angle waves. Kaergaard and Fredsoe [2013a, 2013b] investigated the effect of wave directional spreading, the closure depth $D_{c}$, and the shoreface steepness and showed that sand wave wavelength increases with increasing directional spreading and $D_{c}$, while it decreases with increasing shoreface steepness. However, these studies did not investigate the effect of these parameters on the instability onset. Falqués and Calvete [2005] made a first investigation of the effect of wave conditions on this onset. They essentially found that instability develops only for large wave angle and is favored by small $H$ and small $T$. These authors explored the effect of seven equilibrium profiles, showing that large slope at the shoreline and large bathymetric gradients on the shoreface favor instability onset. However, this exploration has been done for a limited number of bathymetric profiles, and a single closure depth value was considered. Idier et al. [2011] made a systematic exploration of the effect of the wave height, the wave direction, and the surf zone slope: they showed that small wave height and steep surf zones (e.g., a surf zone slope $\beta_{s} \geq 0.04$ ) could lead to instability onset for small angles. Thus, although previous modeling studies investigated the effect of wave conditions, bathymetric profile, and closure depth, a systematic exploration of the instability onset for the whole range of realistic values of such parameters (with the same model) is lacking.

Another important issue is the bathymetric perturbation associated with the shoreline perturbation. It is indeed essential to capture the feedback between the morphology and the wave field. In morphodynamic models where the coastline evolves as a result of the changes in bathymetry driven by the sediment transport, both are linked in a natural way [van den Berg et al., 2012]. However, in models based on the one-line concept, a link must be explicitly set up between shoreline and bathymetric perturbations. Both from observations and from physical principles, little is known on the perturbed bathymetry associated with self-organized sand waves. Therefore, considering that sand waves have a large time scale $O(1-10$ years) in comparison with the short-term event scale of storms, for instance, the assumption of a bathymetric perturbation corresponding to a cross-shore shift of the equilibrium profile following the shoreline displacement has been used [see, e.g., Ashton et al., 2001; Ashton and Murray, 2006a]. Some studies [see, e.g., Falqués and Calvete, 2005; Kaergaard and Fredsoe, 2013a] assumed this profile shift but by imposing a zero perturbation beyond the closure depth $D_{c}$. Falqués and Calvete [2005] considered other perturbations which are exponentially or linearly decreasing from a maximum value at the shoreline to 0 at $D_{c}$. Although some tests looking at different perturbation shapes have been done [Falqués, 2006; Idier et al., 2011], there has been no systematic investigation of the effect of the various types of perturbation and no analysis on the characteristics of the associated perturbed bathymetry and especially on the bathymetric contour curvature, which, as we will show, plays a key role in the development of shoreline sand wave.

The present paper aims to systematically investigate the conditions which can lead to the emergence of kilometer-scale shoreline sand waves from instabilities driven by the alongshore sediment transport. The relative contribution of the physical parameters and the effect of the bathymetric perturbation shape on the instability onset are investigated, with a particular focus on the role of the bathymetric contour curvature and on the critical angle $\theta_{c}$ above which shoreline instability develops. First, the model is presented, the considered bathymetric perturbation shapes are introduced, and their key properties are analyzed, before describing the computer grid experiment (section 2). Then results are presented, and the relative contributions of the physical parameters to the instability onset are analyzed using statistical methods (section 3). Section 4 mainly discusses the sensitivity of the results to the considered perturbation shapes, the associated shoreline sand wave wavelengths, the shoreface slope effect, the plausibility of the perturbation shapes, and the probability to observe the absolute $42^{\circ}$ critical angle in nature. Conclusions are drawn in section 5 . 


\section{Model and Methods}

\subsection{Model Overview}

The 1D-morfo linear stability model is used to investigate the conditions under which shoreline sand waves can emerge from a morphodynamic instability. The model is fully described in Falqués and Calvete [2005], and only the main concepts are presented here along with some details on the shape of the assumed bathymetric perturbation (section 2.2).

A small undulation is imposed on an initially rectilinear shoreline being defined as

$$
y_{s}(x, t)=\frac{a}{2} e^{\sigma t+i k x}+\text { c.c. }
$$

with $x, y$ being cartesian coordinates in the alongshore and cross-shore directions (respectively), $t$ the time, $a$ the amplitude of the shoreline perturbation, $K$ the alongshore wave number $(L=2 \pi / K)$, c.c. the complex conjugate, and $\sigma=\sigma_{r}+i \sigma_{i}$ the complex growth rate (see Figure 1). The model aims at providing $\sigma$, from which the characteristic growth time $\sigma_{r}^{-1}$ and the migration celerity $V=\sigma_{i} / K$ can be computed. A positive growth rate $\sigma_{r}$ means that the shoreline perturbation of wavelength $L$ develops.

Regarding the unperturbed state, the main inputs of the model are the cross-shore bathymetric profile, $z_{b}(y)=-D_{0}(y)$, and the significant wave height, peak period, and angle at a certain depth: $H_{s}$ (in meters), $T_{p}$ (in seconds), and $\theta$ (in degrees). Regarding the perturbation, the main inputs are its alongshore wavelength, $L$, the depth of its offshore reach, $D_{c}$, and its cross-shore shape function, $f(y)$, so that $f(0)=1$ and $f\left(y \geq y_{c}\right)=0$, where $D_{0}\left(y_{c}\right)=D_{c}$. Thus, the perturbed bathymetry associated with the sand wave defined in equation (1) is given by

$$
z_{b}(x, y, t)=-D_{0}(y)+\frac{a}{2} \beta_{s} f(y) e^{\sigma t+i K x}+\text { c.c. }
$$

To compute the growth rate, $\sigma$, equation (1) is inserted into the one-line sediment conservation equation [Komar, 1998]:

$$
\frac{\partial y_{s}}{\partial t}=-\frac{1}{\bar{D}} \frac{\partial Q}{\partial x}
$$

where $\bar{D}$ is a mean depth of the morphodynamic active zone and $Q$ is the total alongshore sediment transport rate. It should be noted that the one-line approximation presupposes that the response of the bathymetry to shoreline changes is instantaneous. Such assumption is justified only on time scales long enough for the sediment accumulation or deficit in the surf zone due to gradients in alongshore transport to be spread to the shoaling zone by the cross-shore exchange until the closure depth $D_{c}$. Such approach makes sense only in a long time scale, not in an event time scale, meaning that the model cannot describe the response to individual events such as storms. However, storms still play a significant role in the model behavior as they affect the closure depth $D_{c}$ but in a statistical way [Hallermeier, 1978].

In equation (3), $Q$ is computed with the Coastal Engineering Research Center (CERC) formula [Komar, 1998]:

$$
Q=\mu H_{b}^{5 / 2} \sin 2 \alpha_{b}
$$

where $H_{b}, \alpha_{b}$ are the wave height and wave angle with respect to the local shore normal at breaking and $\mu$ is an empirical constant. The constant $\mu$ (typical values of $\approx 0.1-0.2 \mathrm{~m}^{1 / 2} \mathrm{~s}^{-1}$ ) is proportional to the empirical parameter $K_{1}$ of the original CERC formula. It is set up to $\mu=0.15 \mathrm{~m}^{1 / 2} \mathrm{~s}^{-1}$, which corresponds to $\mathrm{K} 1=0.525$ [see Idier et al., 2011]. The value of $\mu$ has an effect only on the time scale, such that the sign of the growth rate $\sigma_{r}$ (i.e., the shoreline instability onset) is insensitive to the magnitude of this parameter.

Computing the left-hand side of equation (3) is straightforward from equation (1), but estimating the right-hand side requires calculating the perturbed $H_{b}$ and $\alpha_{b}$. This is done by linearizing (with respect to $a$ ) the equations describing refraction and shoaling over the perturbed bathymetry and computing $H_{b}$ and $\alpha_{b}$ numerically.

On many beaches, the long-term averaged equilibrium profile can be represented by a Dean profile [Dean, 1977]. Thus, for the present analysis, we use a shifted Dean-type bathymetric profile, $D_{0}(y)=A\left(\left(y+y_{0}\right)^{2 / 3}-\right.$ $\left.y_{0}^{2 / 3}\right)$, which is characterized by the $A$ coefficient and the $y_{0}$ parameter that introduces a small shift to avoid an infinite slope at the shoreline [Falqués and Calvete, 2005]. We compute $y_{0}$ by prescribing the shoreline slope $\beta_{s}$, so that the bathymetric profile is fully defined by the two parameters $A$ and $\beta_{s}$. Although $\beta_{s}$ is (in the model) the slope right at the shoreline, its real meaning is the mean slope of the area where the littoral drift takes place (i.e., roughly the surf zone) since 1D-morfo is a one-line model so that this area collapses in a single line. 


\section{Example}

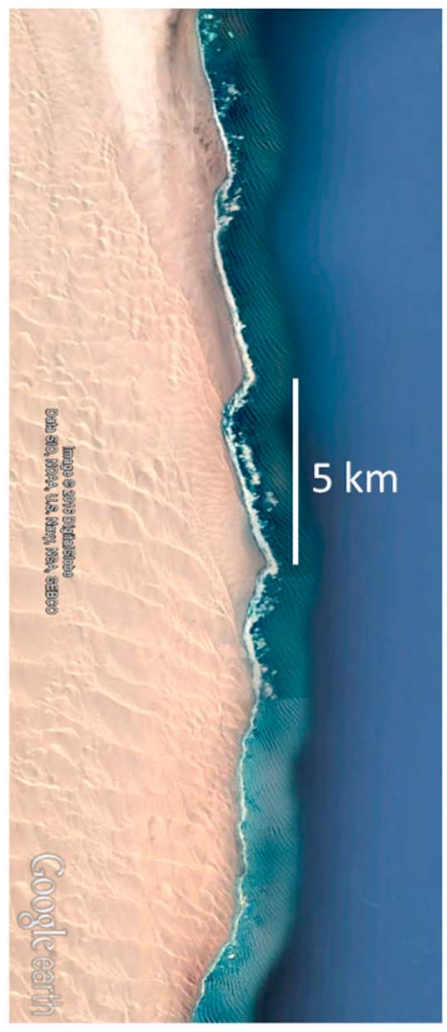

(a)
Model geometry

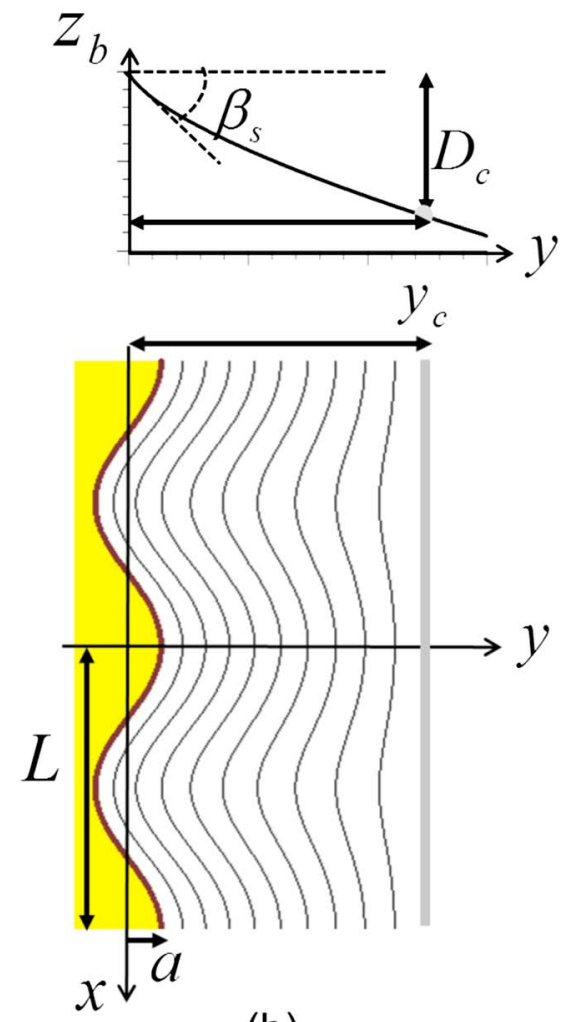

(b)

Figure 1. (a) Shoreline sand wave example (location: $23.8^{\circ} \mathrm{N}, 14.5^{\circ} \mathrm{E}$ ) and (b) model geometry (cross and top view).

\subsection{Bathymetric Perturbation: Description and Role of the Associated Curvature}

First, the cross-shore shape function (equation (2)) is such that $f(0)=1$ and $f\left(y \geq y_{c}\right)=0$ (see section 2.1). Second, as highlighted in section 1, different types of bathymetric perturbation have been used in previous studies. The investigated perturbation shapes can be split into two classes: one based on profile shift assumptions and the other based on a prescribed decay of the bed level perturbation. Two examples of bathymetric perturbations are provided in Figure 2, for low and high bathymetric gradients profiles. The associated perturbation shapes can be written as follows:

$$
\begin{aligned}
& P 1: f(y)=\frac{1}{\beta_{s}} \frac{\mathrm{d} D_{0}}{\mathrm{~d} y} \\
& P 2: f(y)=1-\frac{y}{y_{c}}
\end{aligned}
$$

The shape function P1 (equation (5)) was defined and used by Falqués and Calvete [2005]. By inserting it in equation (2) and considering equation (1), it is readily seen that it corresponds to horizontally shifting the profile by the same amount as the shoreline displacement. The shape function P2 is based on a linear decay of the bed level perturbation (equation (6)). Such perturbation is obtained as a limit of the exponential perturbation used in Falqués and Calvete [2005] in case of very large value of the $e$-folding distance controlling the seaward decay, i.e., the distance over which the bed level perturbation decays by a factor of $\exp (1) \simeq 2.7$.

For the high bathymetric gradient, both options show similar (but not exactly equal) horizontal patterns (Figure 2b), whereas for the low bathymetric gradient, P2 exhibits significant differences with a curvature of the bathymetric lines which reaches a maximum at a certain distance from the coast (Figure 2a).

We here make a preliminary analysis of this curvature property on shoreline sand wave development. First, wave refraction by slowly varying depth contours can be represented by wave rays, which are locally 


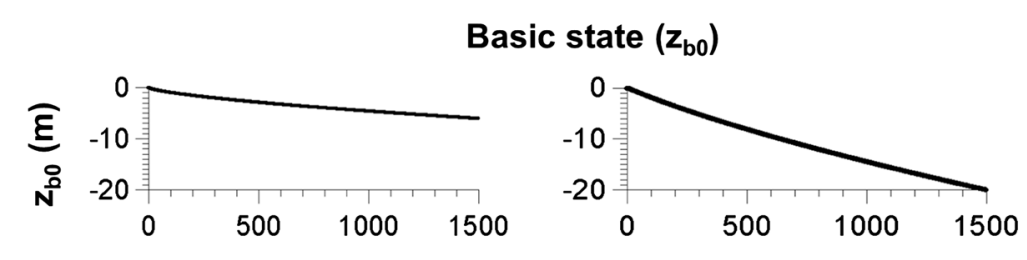

Perturbation shape (f)
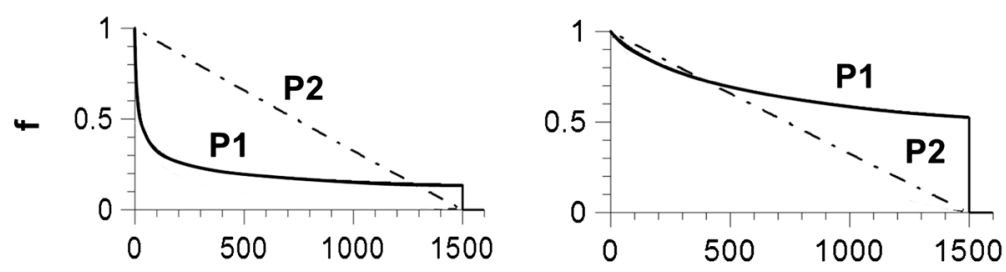

Perturbed bed level $\left(z_{b}\right.$, in meter) $\mathrm{Z}_{\mathrm{b}}(\mathrm{P} 1)$ : color ; $\mathrm{Z}_{\mathrm{b}}(\mathrm{P} 2)$ : contour

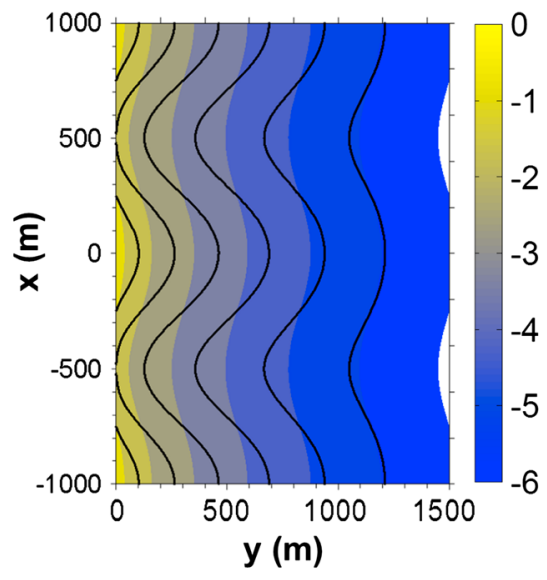

(a)

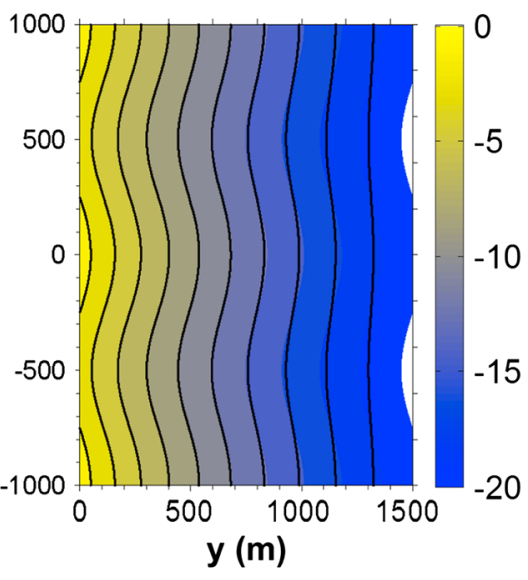

(b)

Figure 2. Basic state (cross-shore), perturbation shapes (cross-shore), and perturbed bed level (plan view) for two basic profiles: (a) $A=0.047 \mathrm{~m}^{1 / 3}$ and (b) $A=0.190 \mathrm{~m}^{1 / 3}$, with $\beta_{\mathrm{s}}=0.02$ for both profiles. In addition, the shown perturbations are such that $D_{c}$ equals $6 \mathrm{~m}$ and $20 \mathrm{~m}$ for Figures $2 \mathrm{a}$ and $2 \mathrm{~b}$, respectively. The corresponding $\Omega$ value is 0.043 (Figure 2a) and 0.86 (Figure 2b).

perpendicular to the wave fronts [Mei, 1989]. In case of curvilinear depth contours, the bathymetry can be locally approximated by circular contours. Then, the following generalized Snell law $k r \sin \theta=C_{0}$ is valid, where $C_{0}$ is a constant, $k$ is the wave number, $r$ is the distance to the center of curvature, and $\theta$ is the angle between wave rays and the local normal to the contours [Mei, 1989]. Then, if $\theta \neq 0$ in deep water, it can never be 0 in shallower water, and, as a result, wave rays approaching with certain angle can never cross the normal to the bathymetric lines.

One of the main differences between the work of Idier et al. [2011] and other shoreline sand wave studies is the existence (or not) of a critical angle or, in other words, if LAWI is active or not. Therefore, it is useful to focus on the case of offshore waves characterized by an incidence angle normal to the coast $\left(\theta=0^{\circ}\right)$. In this case the growth of a bump in the shoreline needs a sediment flux, $Q$, directed toward the tip at both sides of the bump. If the depth contours are parallel to the shoreline (P1), this means that the wave rays should cross the normal to the depth contours, which is impossible according to the generalized Snell law. Therefore, LAWI can never occur if a P1 perturbation is assumed.

The situation is different in case of a P2 perturbation, because the depth contours are no longer parallel to the shoreline and their undulations could in fact be more pronounced than the shoreline undulation (see Figure 2a). If this is the case, the rays can cross the normal to the shoreline without crossing the local normal to the depth contours during refraction. In this case the sediment fluxes converge at the tip so that LAWI 


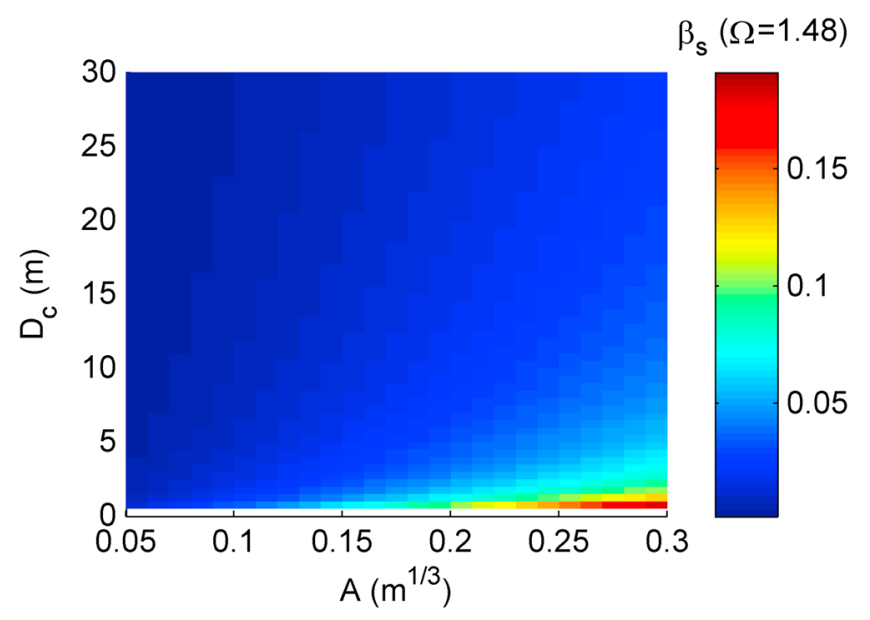

Figure 3. Critical surf zone slope $\beta_{s}(\Omega=1.48)$ for given values of the closure depth $D_{c}$ and shoreface slope coefficient $A$. For given values of $D_{c}$ and $A$, a necessary condition for low-angle instabilities is $\beta_{s}>\beta_{s}(\Omega=1.48)$.

could occur. To examine this possibility, we compute the maximum angle $(\phi)$ between a perturbed bathymetric contour and the mean shoreline. By linearizing with respect to $a$ the real part of equation (2) for $t=0$, this angle is given by

$$
\tan \phi=a \beta_{s} K \frac{f(y)}{D_{0}^{\prime}(y)}
$$

By inserting the Dean-type profile $D_{0}(y)$ and the P2 shape function $f(y)$, one obtains

$$
\tan \phi=\frac{3 a}{2} \frac{\beta_{s} K}{A y_{c}} F(y)
$$

where $F(y)=\left(y_{c}-y\right)\left(y+y_{0}\right)^{1 / 3}$. This function has a maximum at $y_{m}=\left(y_{c}-3 y_{0}\right) / 4$. If $y_{m}>0$, there is a region between the shoreline, $y=0$, and a certain offshore location, $y_{1}\left(>y_{m}\right)$, where the curvature of the depth contours is larger than the curvature of the shoreline. By using equation (27) of Falqués and Calvete [2005] that gives $y_{0}$ as a function of $A$ and $\beta_{s}$ and after some algebra, one obtains the location $y_{m}$ of maximum bathymetric curvature:

$$
y_{m}=\frac{1}{4}\left(\frac{D_{c}}{A}\right)^{3 / 2}\left(\left(1+\frac{4}{9} \Omega\right)^{3 / 2}-\frac{32}{27} \Omega^{3 / 2}\right)
$$

where, $\Omega=A^{3} / D_{c} \beta_{s}^{2}$ is a dimensionless parameter. It can be seen that $y_{m}>0$ for

$$
\Omega=\frac{A^{3}}{D_{c} \beta_{s}^{2}}<\frac{9}{4-2^{10 / 3}} \simeq 1.48
$$

Thus, equation (10) provides a necessary condition for having LAWI in case of a P2 perturbation and shows that LAWI should be favored by small $A$, large $D_{c^{\prime}}$ and large $\beta_{s}$. Such result is consistent with the conclusion of Idier et al. [2011] who found that instabilities can develop in cases of low-angle or shore normal incidence under the condition of large enough beach slope and large enough cross-shore extension of the bed perturbation (i.e., large enough closure depth in the case of a P2 perturbation). As soon as $\Omega \geq 1.48, y_{m}$ is located at the shoreline, as for the P1 perturbation. Figure 2 illustrates the effect of an increase of $A$ (i.e., $\Omega$ ) on the bathymetric undulations. For the small $A$ value $(\Omega=0.043$, Figure $2 \mathrm{a})$, bathymetric undulations are maximum at a certain distance from the coast, while for large $A(\Omega=0.86$, Figure $2 \mathrm{~b}$ ), they reach a maximum closer to the shoreline such that the $\mathrm{P} 2$ bathymetric contours are quite similar to the $\mathrm{P} 1$ ones. This analytical development suggests that we should observe similar results (e.g., similar critical wave angle $\theta_{c}$ ) between the P1 and P2 perturbations for large $A$ and small $\beta_{s}$. As soon as $\Omega \geq 1.48$, only HAWI can develop in the case of a P2 perturbation. To illustrate the physical conditions corresponding to the critical value $\Omega=1.48$, assuming physical ranges for $D_{c}$ and $A$, we compute the slope $\beta_{s}(\Omega=1.48)$ (Figure 3). For given $A$ and $D_{c}$ values, if $\beta_{s}$ is smaller than $\beta_{s}(\Omega=1.48)$, then there is no possibility to observe low-angle instability (as $y_{m}$ is located at the shoreline). 
Table 1. Design of Computer Experiments ${ }^{\mathrm{a}}$

\begin{tabular}{lcccccc} 
& $\theta(\mathrm{deg})$ & $\beta_{s}$ & $A\left(\mathrm{~m}^{1 / 3}\right)$ & $D_{c}(\mathrm{~m})$ & $H_{s}(\mathrm{~m})$ & $T_{p}(\mathrm{~s})$ \\
\hline Min & 0 & 0.01 & 0.05 & 2.5 & 0.25 & 4 \\
Max & 85 & 0.5 & 0.3 & 27.5 & 4 & 16 \\
$\Delta$ & 5 & 0.01 to 0.1 & 0.05 to 0.1 & 2.5 & 0.25 & 1 \\
$N$ & 18 & 16 & 4 & 6 & 16 & 13 \\
\hline
\end{tabular}

${ }^{a}$ The range (Min to Max), the sampling step $(\Delta)$, and the grid size $(N)$ are provided for each of the following input parameters used for the stability analysis computations done with the 1D-morfo model: wave angle $\theta$, surf zone slope $\beta_{s}$, shoreface slope coefficient $A$, closure depth $D_{c}$, wave height $H_{s}$, and wave period $T_{p}$.
The $\Omega$ condition is necessary but not sufficient to trigger LAWI: another necessary condition is that $y_{1}>y_{b}\left(y_{b}\right.$ is the position of the unperturbed breaking line), i.e., the region where the curvature of the depth contours is larger than the curvature of the shoreline extends offshore the surf zone such that the refractive bending of the rays before breaking can be stronger than the rotation of the shoreline. This second necessary condition of a narrow (enough) breaking zone depends on both the wave conditions and the $A$ coefficient. The above analysis suggests that the conditions prone to sand wave formation for any wave angle (i.e., also for low angles) are large $\beta_{s}$, small $A$, and large $D_{c}$ (i.e., small $\Omega$ ) but also small wave period and wave height.

\subsection{Computer Experiment Setup}

To confirm this analysis and investigate the effect of the physical and model parameters on the instability onset, a systematic analysis is done by performing a model grid experiment in the space $\left(\theta, \beta_{s}, A, D_{c}, H_{s}, T_{p}\right)$. A wide range of physically possible parameter values on sandy coasts is explored (Table 1).

For each configuration $\left(\theta, \beta_{s}, A, D_{c}, H_{s}, T_{p}\right)$ we computed the growth rate with the 1D-morfo model for shoreline perturbations of wavelengths $L$ ranging from $10 \mathrm{~m}$ to $50 \mathrm{~km}$, with a step of $100 \mathrm{~m}$ (i.e., for 500 different wavelengths). The shoreline is considered unstable when at least one perturbation within the wavelength range is amplified (i.e., $\max \left(\sigma_{r}(L)\right)>0$ ). A large enough wavelength range is considered in order to ensure capturing the unstable wavelengths at their initiation stage. It should be noted that this study focuses on the conditions leading to shoreline instability, rather than on characteristics of the linearly most amplified modes such as the wavelength (for further information on these characteristics, see, for instance, the study of Idier et al. [2011] which covers the entire range of wave incidence angle, but for a limited number of configurations, and section 4.2 for a statistical analysis of the wavelengths of the linearly most amplified modes obtained from the grid experiment).

The range of the parameters $H_{s}$ and $T_{p}$ are representative of yearly averaged wave conditions encountered along the world coasts. They are estimated using global wave model results analysis. The wave data come from a global wave hindcast done using the Climate Forecast System Reanalysis (CFSR) wind data and the WAVEWATCH III model (spatial resolution of $0.5^{\circ}$, temporal resolution of $3 \mathrm{~h}$ ), within the IOWAGA project [Rascle and Ardhuin, 2013]. This wave hindcast is also used to estimate the range of possible $D_{c}$ values on a decade scale by using the Hallermeier formula [Hallermeier, 1981]. The values of $A$ and $\beta_{s}$ are selected based on existing literature and physical considerations. We choose a maximum value of $A=0.3 \mathrm{~m}^{1 / 3}$ based on the Dean [1987] relationship between the fall velocity and $A$, which for coarse sand of $2 \mathrm{~mm}$ gives $A=0.25 \mathrm{~m}^{1 / 3}$. As a comparison, existing shoreline sand wave studies using a Dean profile [Falqués and Calvete, 2005; Kaergaard and Fredsoe, 2013a, 2013b; Uguccioni et al., 2006; van den Berg et al., 2012; Idier et al., 2011] considered $A$ coefficients falling in the range $0.08-0.2 \mathrm{~m}^{1 / 3}$. For the maximum value of $\beta_{s}$, a value of 0.2 would be justified according to the literature [e.g., Wright and Short, 1984]. However, to account for the inherent degree of uncertainty and some possible extremely steep surf zones, we extend the $\beta_{s}$ range to 0.5 . In addition, to ensure considering physical values, three constraints have been taken into account in the computer grid experiment design: (C1) the critical wave steepness, (C2) the consistency between surf zone slope and shoreface shape, and (C3) the closure depth versus the wave conditions. Indeed, waves are characterized in nature by a maximum steepness, such that the wave period $T_{p}$ cannot be smaller than a given value for a given wave height $H_{s}$. The Pierson and Moskowitz [1964] criterion is used to estimate the minimum wave period versus the wave height (constraint $\mathrm{C} 1$ ). Regarding the bathymetric profile, the mean surf zone slope $\beta_{s}$ cannot be smaller than the mean shoreface slope $D_{c} / y_{c}$ (constraint $C 2$, see Figure 1). This leads to the constraint that the minimum value of $\beta_{s}$ depends on $A$ and on $D_{c}$. Finally, the closure depth $D_{c}$ (obtained considering the wave conditions corresponding to the $12 \mathrm{~h}$ exceeding wave height over a given time span; see Hallermeier [1981]), by definition, cannot be smaller than the closure depth that we would obtain using mean wave climate conditions 

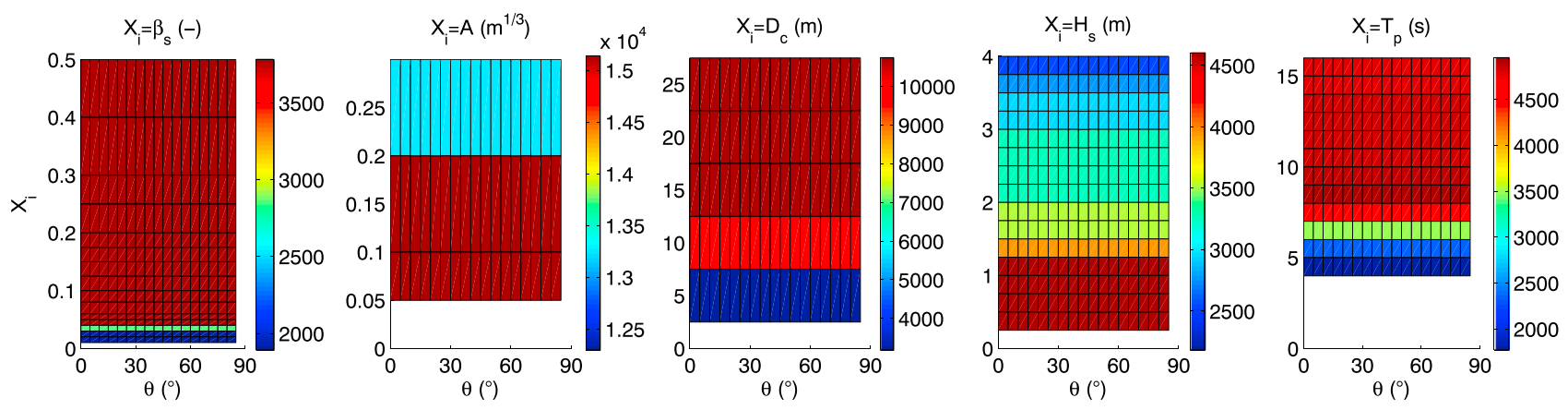

Figure 4. Number of simulations per pair of values $\left(\theta, X_{i}\right)$. In each panel, the total is equal to $1,004,652$.

(constraint C3). These constraints imply that the grid experiment is not uniform; i.e., the number of simulations per bin is not constant (as shown by the nonuniform colors in each panel of Figure 4). For instance, focusing on the distributions of the computations versus the slope $\beta_{s}$ (Figure 4, first panel), the number of simulations per bin $\left(n_{b}\right)$ is not constant ( $n_{b}$ is constant for $\beta_{s} \geq 0.04$ but not for smaller $\beta_{s}$ values). This is due to the C2 constraint. The grid experiment data set represents 1,004,652 (i.e., about 1 million) simulations per bathymetric perturbation type. Each run costs $1.2 \mathrm{~s}$ of computation on one CPU (central processing unit), such that the computational effort, in CPU unit, represents 14 days for each perturbation type. The computations have been done on 40 CPUs.

\section{Results}

\subsection{General Trends}

For each configuration $\left(\beta_{s}, A, D_{c}, H_{s}, T_{p}, \theta\right)$, the model provides the maximum growth rate $\left(\max \left(\sigma_{r}(L)\right)\right)$ for the explored range of wavelength ( $10 \mathrm{~m}$ to $50 \mathrm{~km}$ ), i.e., a single deterministic value. If this value is positive, then there is instability (shoreline sand waves develop).

Analyzing results in the six-dimension space of the input parameters $\left(\beta_{s}, A, D_{c}, H_{s}, T_{p}, \theta\right)$ raises the issue of the visualization for high-dimension problems. To tackle this issue, we analyze the results in terms of probability of shoreline sand wave development in two-dimension spaces. This is done by defining the probability $p_{s}\left(\theta, X_{i}\right)$ (with $i=1$ to 5 and $\left.X=\left(\beta_{s}, A, D_{c}, H_{s}, T_{p}\right)\right)$ as the ratio of the number of experiments for which instability develops for a given bin $\left(\theta, X_{i}\right)$ to the total number of experiments done in this bin. For instance, the probability $p_{s}\left(\theta=85^{\circ}, D_{c}=25 \mathrm{~m}\right)$ is equal to the number of cases where instability develops in the space $\left(\beta_{s}, A, D_{c}=25 \mathrm{~m}, H_{s}, T_{p}, \theta=85^{\circ}\right)$ divided by the total number of runs done in this space (see Figure 5a3).

As highlighted in section 2.3, the grid experiment is not uniform (Figure 4). To better highlight the general trend avoiding side effect due to the nonuniformity, in addition to the "all grid" data set, we consider two uniform subsets. Both subsets include the entire range of wave angle and shoreface slope but exclude the surf zone slopes smaller than 0.04 . Subset 1 includes the entire range of wave height $H_{s}$ but includes only the largest values of $D_{c}(10-27.5 \mathrm{~m})$ and $T_{p}(8-16 \mathrm{~s})$, while subset 2 includes the entire range of $D_{c}$ and $T_{p}$ but includes only the lowest wave height values $(0.25-1 \mathrm{~m})$.

Figure 5 shows the probability of shoreline sand wave development $p_{s}\left(\theta, X_{i}\right)$ for the $\mathrm{P} 1$ and $\mathrm{P} 2$ perturbations. First, although the perturbation shapes P1 (profile shift) and P2 (linear bed level decay) may be relatively similar in some cases (see, e.g., Figure $2 \mathrm{~b}$ ), the probability patterns strongly differ when comparing Figures $5 \mathrm{a}$ and $5 \mathrm{~b}$. The most crucial difference is that for $\mathrm{P} 1$, there is an (absolute) critical angle $\theta_{c 0}\left(\sim 42.5^{\circ} \pm 2.5^{\circ}\right)$, below which $p_{s}=0$ whatever the physical parameters, whereas for $\mathrm{P} 2$, even though $p_{s}$ increases with the angle, there is no critical angle. Thirty-three percent of the runs done over the entire space $\left(\theta, \beta_{s}, A, D_{c}, H_{s}, T_{p}\right)$ exhibit the same results (instability/stability) for both perturbation shapes, i.e., $\max \left(\sigma_{r}(L)\right)>0$ or $\max \left(\sigma_{r}(L)\right) \leq 0$.

In addition to the effect of the perturbation shape, Figure 5 allows analyzing the dependency of the instability onset on the physical parameters. To avoid misinterpretation of the results, we now consider the $p_{s}$ values obtained for the uniform subsets 1 and 2 . Focusing on perturbation shape P1 in areas of potential instability (i.e., where $p_{s}>0$ ), the probabilities are overall smaller than for the P2 shape (Figures $5 \mathrm{a}$ and $5 \mathrm{~b}$ ). The probability tends to 1 only for oblique waves characterized by small wave periods, meaning that in such case, there would be instability whatever the values of the other parameters. The probability $p_{s}$ increases 


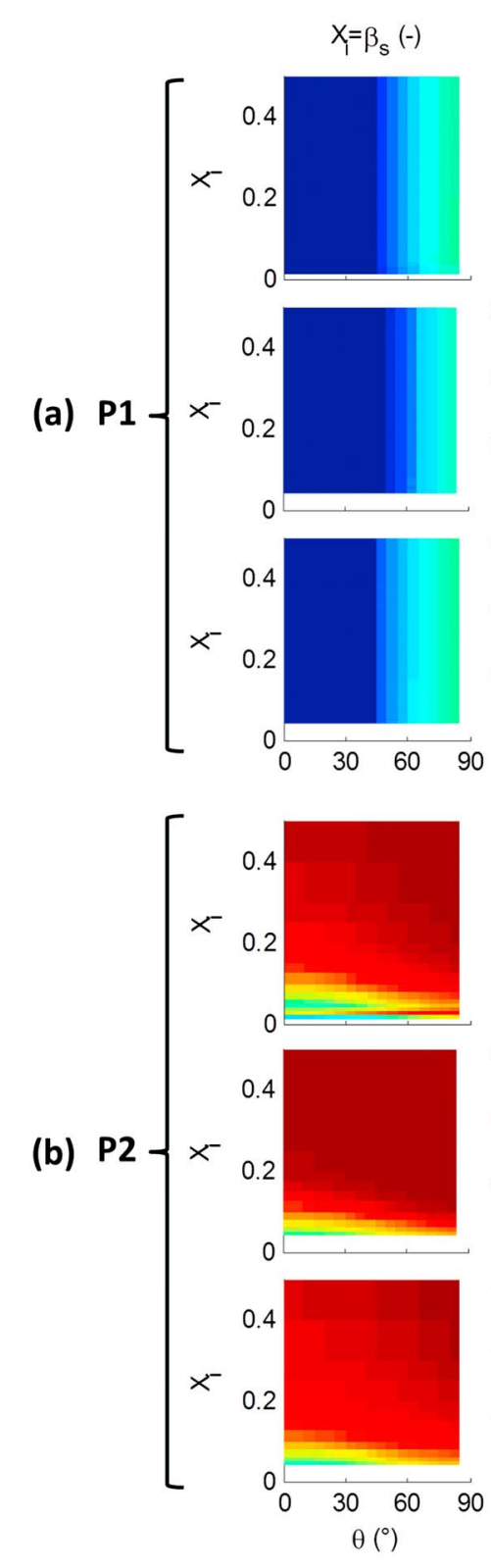

(1)
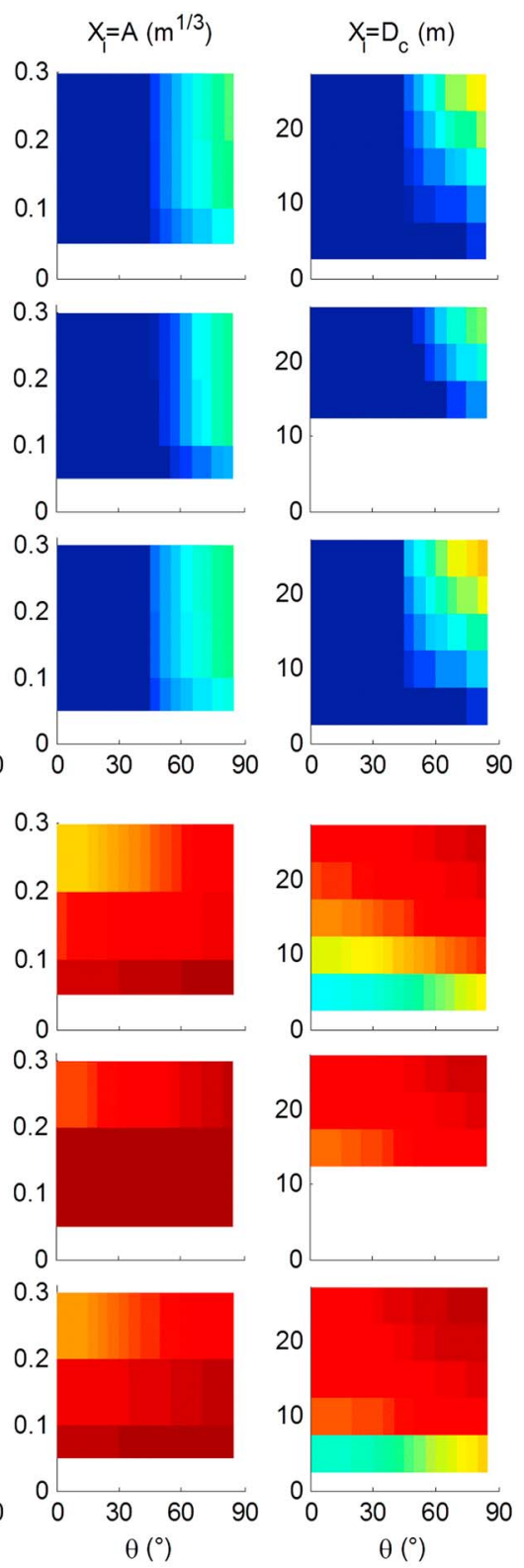

(2)

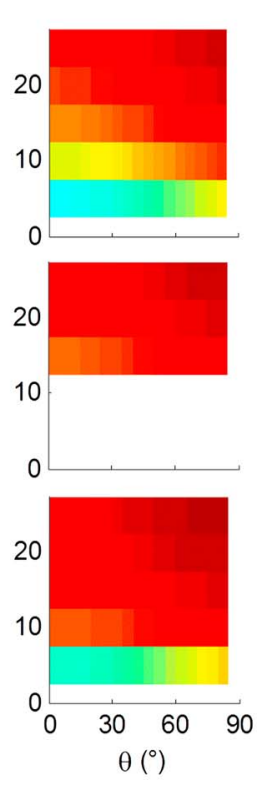

(3)
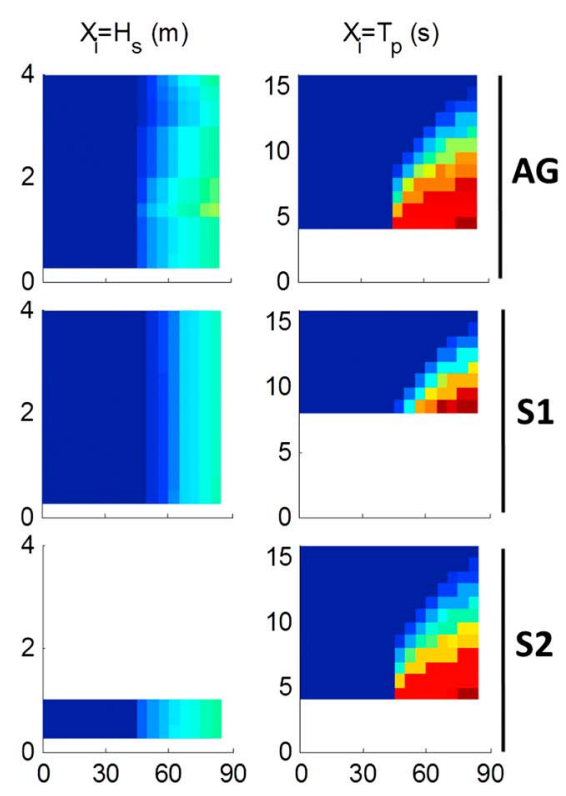

S1

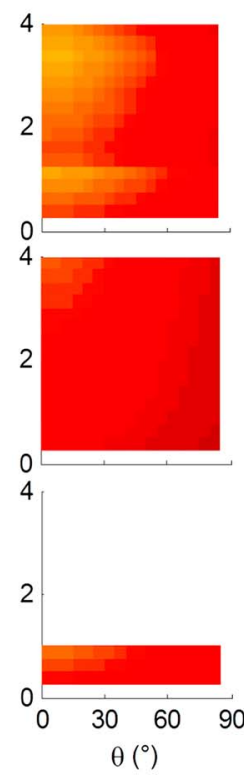

(4)

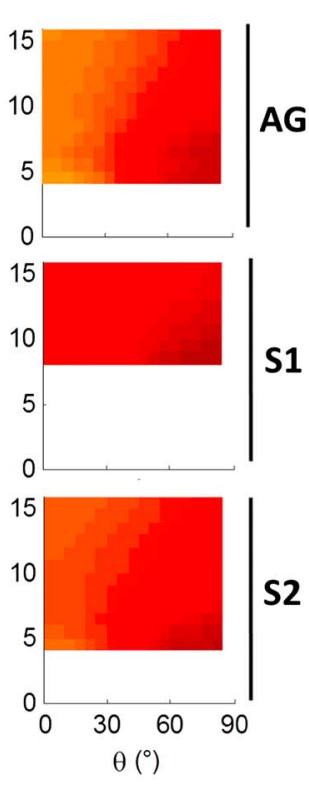

(5)

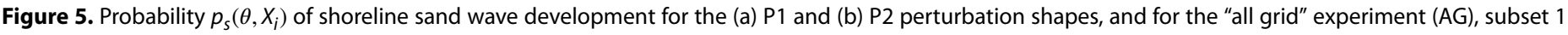

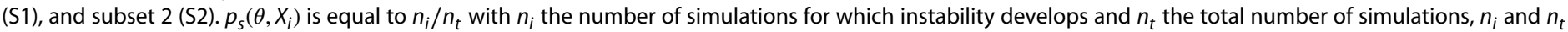
being computed over the experiment subset $\left(\theta, X_{i}\right)$. For instance, $p_{s}\left(\theta=30^{\circ}, \beta_{s}=0.2\right)=n_{i} / n_{t}$ with $n_{i}$ and $n_{t}$ computed over the experiment subset $\left(\beta_{s}=0.2, A, D_{c}, H_{s}, T_{p}, \theta=30^{\circ}\right)$. On the "AG" plots, some discontinuities can be observed. They are related with the nonuniformity of the grid experiment

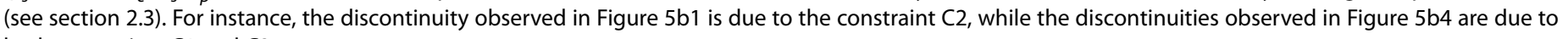
both constraints $\mathrm{C} 1$ and $\mathrm{C} 3$.

with $D_{c}$, while there is a slight influence of $A$ and no influence of the surf zone slope $\beta_{s}$ and wave height $H_{s}$. Figure 5 suggests the following ranking (from dominant to minor) of the parameters contributions: $\theta$ and $T_{p}$, $D_{c}, A$. The null effect of $\beta_{s}$ can be readily seen by replacing the $\mathrm{P} 1$ perturbation shape function $f(y)$ provided by equation (5) in the model equation (2), as $\beta_{s}$ cancels in this case.

Regarding the P2 perturbation, $\beta_{s}$ and $A$ have a positive and negative effect, respectively (Figures $5 \mathrm{~b} 1$ and $5 \mathrm{~b} 2$ ). Thus, the two parameters characterizing the bathymetric profile play opposite roles. Indeed, small $A$ values lead to stronger wave refraction, whereas large surf zone slope $\beta_{s}$ leads to a smaller surf zone width. According to Idier et al. [2011] who assumed perturbations similar to the P2 type, large refraction and small 
surf zone width favor shoreline sand wave development, especially for low incidence angle. The negative effect of $A$ for the P2 perturbation will be further discussed in section 4.3. Regarding the closure depth $D_{c}$, it has a positive effect (Figure 5b3), while the wave period $T_{p}$ and height $H_{s}$ have a negative effect on shoreline instability development (Figures $5 \mathrm{~b} 4$ and $5 \mathrm{~b} 5$ ). In terms of relative influence of the parameters, the variations of probability induced by each parameter suggest that $\beta_{s}, \theta, A$, and $D_{c}$ have significant effects, while $H_{s}$ and $T_{p}$ have minor effects on the instability onset. These results overall confirm the findings of previous work. For example, Falqués and Calvete [2005] found, for the same perturbation type, that increasing the wave steepness or decreasing wave height tend to strengthen instability. Idier et al. [2011] showed that increasing $\beta_{s}$ or $D_{c}$ favors instability. Both papers provided an explanation of the related physical mechanisms. But what was not clearly identified before is the relative effect of the bathymetric profile $\left(\beta_{s}\right.$ and $\left.A\right)$ and the relative contribution of the other parameters.

The negative $(A)$ and positive effects $\left(\beta_{s}\right.$ and $\left.D_{c}\right)$ drawn from the numerical computations are consistent with the preliminary analysis done in section 2.2 which highlights the necessary condition for instability in case of normal wave incidence $\Omega=A^{3} / D_{c} \beta_{s}^{2}<1.48$ (i.e., a curvature of the bathymetric contours larger than the one at the shoreline). In addition, the analysis of the grid experiment results shows that the $\Omega$ values of the unstable configurations range between 0 and 0.3 and that the critical value of $\Omega$ below which instability occurs also depends on $D_{c}, H_{s}, T_{p}$ (see Figure $\mathrm{S} 1$ in supporting information). This is consistent with our conclusion of section 2.2: instability should be triggered only when the bathymetric curvature offshore the breaking line is larger than the shoreline one (i.e., under the necessary condition that $\Omega$ is smaller than 1.48 and a narrow enough breaking zone). Considering the entire range of wave direction, only 32 configurations over the 829,921 instability cases exhibit an $\Omega$ value larger than 1.48 . These 32 configurations exhibit a wave incidence angle $\theta \geq 60^{\circ}$.

To summarize, the perturbation shape and the related bathymetric curvature play a key role, while instability onset is favored by large wave incidence $(\theta)$, large closure depth $\left(D_{c}\right)$, and small wave period $\left(T_{p}\right)$, whatever the perturbation type.

\subsection{Relative Influence of the Parameters Versus Wave Angle}

The effect of the physical parameters depends on the wave angle (as shown in Figure 5). To better assess this dependence, we compute the ratio $R_{X_{i}}(\theta)=\left(p_{s}\left(\theta, \max \left(X_{i}\right)\right)+1\right) /\left(p_{s}\left(\theta, \min \left(X_{i}\right)\right)+1\right)$, for each parameter $X_{i}$, with $X=\left(\beta_{s}, A, D_{c}, H_{s}, T_{p}\right) \cdot R_{X_{i}}(\theta)>1\left(R_{X_{i}}(\theta)<1\right)$ means that for a given wave angle, an increase of $X_{i}$ leads to an increase (decrease) of the probability of shoreline sand wave development. $R_{X_{i}}(\theta)=1$ means that for this $\theta$ value the $X_{i}$ parameter has no effect. A constant $R_{X_{i}}(\theta)$ means that the effect of the parameter $X_{i}$ is independent of $\theta$. Thus, if $R_{X_{i}}(\theta)$ goes close to 1 for increasing $\theta$, this means that the effect of the parameter $X_{i}$ is decreasing with $\theta \cdot R_{X_{i}}(\theta)$ is computed for the entire grid experiment (set called "all grid") but also for subsets 1 and 2 .

First, we focus on the results obtained with a P2-type perturbation for subset 1. In agreement with the results of section 3.1 (Figures $5 \mathrm{~b}-\mathrm{S} 1$ ), $\beta_{s}$ and $A$ have the largest effects (positive for $\beta_{s}$ and negative for $A$ ), while $D_{c^{\prime}}$ $H_{s}$, and $T_{p}$ have smaller effects (Figure $6 \mathrm{~b}$, bottom). $H_{s}$ has a negative effect whose amplitude decreases with $\theta$. In addition, the effects of the cross-shore profile $\left(\beta_{s}\right.$ and $\left.A\right)$ and the closure depth $D_{c}$ are enhanced by low wave angles. Finally, the amplitude of the contribution of $T_{p}$ increases with increasing wave angle until $\theta=60^{\circ}$ and then decreases, whereas the amplitude of the other contributions mainly decreases with the wave angle. In terms of relative contribution, it should be recalled that the above analysis is done for subset 1 where the smallest values of $D_{c}$ and $T_{p}$ of the grid experiment are not included (see section 3.1). Selecting subset 2, which includes these small values but excludes the large values of $H_{s}$, leads to similar curves but with larger $R_{D_{c}}$ values and larger variations of $R_{D_{c}}$ with $\theta$. These results are confirmed when taking into account the entire grid experiment (Figure $6 \mathrm{~b}$, top): in case of a P2 perturbation, the dominant parameters appear to be $\beta_{s}, A$, and $D_{c}$.

The P1 perturbation exhibits a different behavior (Figure 6a, top). First, consistently with the existence of an absolute critical angle $40^{\circ}<\theta_{c 0}<45^{\circ}$ observed in section $3.1, R_{X_{i}}=1$ until $\theta=40^{\circ}$. Focusing on subsets 1 and 2, Figure 6 a (bottom) also shows that $A$ has a positive effect (contrary to P2) which increases with $\theta ; D_{c}$ has a significant positive effect (as P2) mainly increasing with $\theta$ (contrary to P2); $T_{p}$ has a significant negative effect (as P2), whose amplitude increases with $\theta$ (as P2 for $\theta \leq 60^{\circ}$ ); and $\beta_{s}$ and $H_{s}$ have no effect (contrary to $\mathrm{P} 2$ ). The more striking difference with the case of a P2 perturbation is the positive effect of $A$. This will be discussed in section 4.3. 


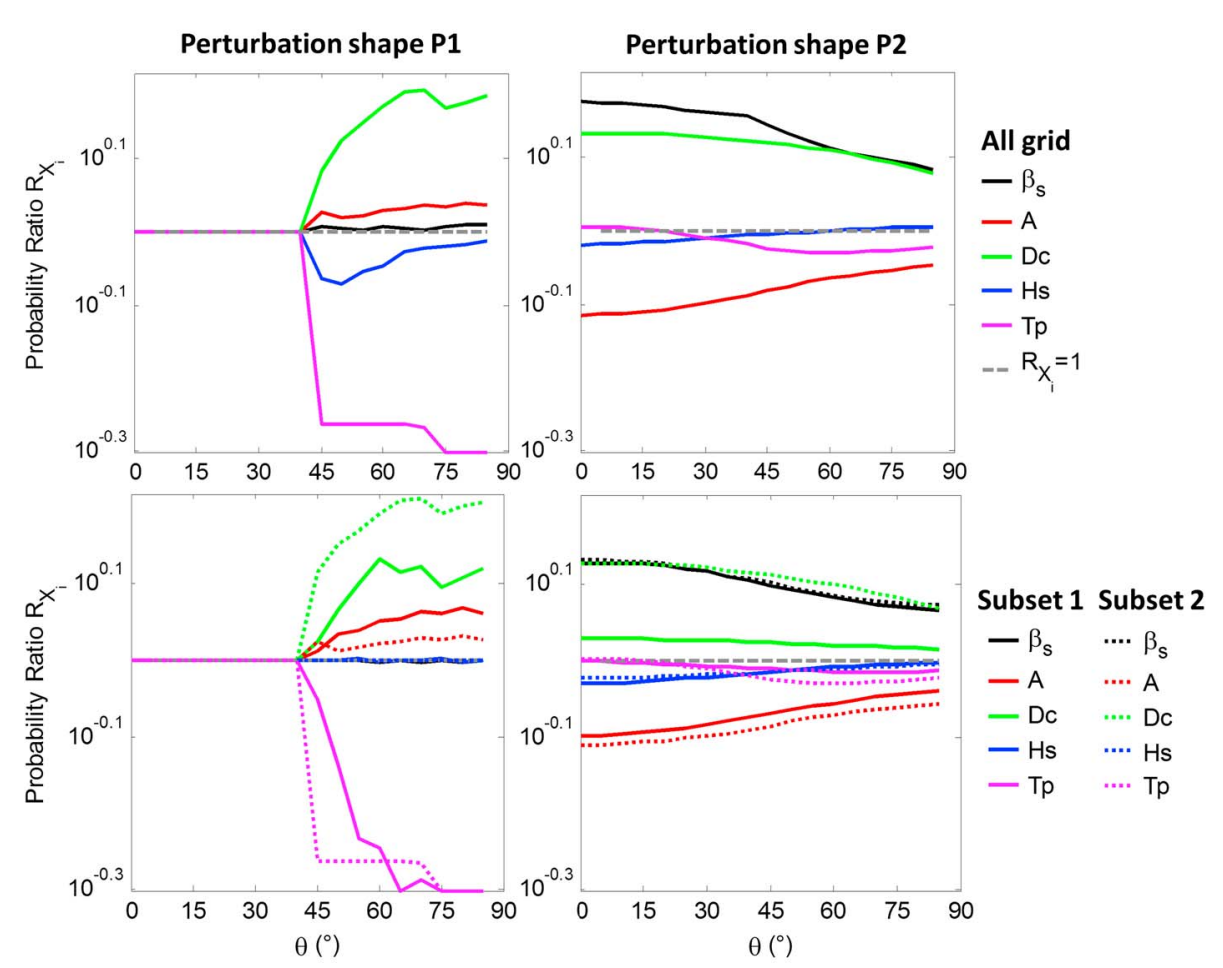

(a)

(b)

Figure 6. Probability Ratio $R_{X_{i}}$ versus wave angle $\theta$ considering each parameter $X_{i}$, and for perturbation shapes (a) P1 and (b) P2. (top row) $R_{X_{i}}$ is computed using the entire grid experiment results ("All grid"). (bottom row) $R_{X_{i}}$ is computed using subsets 1 and 2 (described in section 2.3) such that within each subset, for any parameter $X_{i}$, exactly the same combinations of parameters $X_{j}$ are considered with $j \neq i$. This figure shows how the effect of each parameter varies with the wave incidence angle: a decrease (increase) in $\left|R_{X_{i}}-1\right|$ means that the effect of the $X_{i}$ parameter decreases (increases) with the angle.

\subsection{Critical Wave Angles $\theta_{c}$ and $\theta_{c 0}$}

The variations of the $p_{s}=0$ contours with the parameters $X_{i}$ (see, e.g., subsets 1 and 2 in Figure 5 ) indicate that for a P1 perturbation, changes in $\beta_{s}$ and $H_{s}$ do not affect the critical angle $\theta_{c}$, while the increase of $D_{c}$, of $T_{p}$, and to a smaller extent of $A$ leads to a decrease of $\theta_{c}$. For the P2 perturbation, the changes in $p_{s}$ indicate that $\theta_{c}$ decreases with $\beta_{s}$ and $D_{c}$, while it increases with $A$ and $H_{s}$ and hardly changes with $T_{p}$.

As highlighted above, in the $\mathrm{P} 1$ case, whatever the parameters $\left(\beta_{s}, A, D_{c}, H_{s}, T_{p}\right)$, there is an absolute critical wave angle over the entire experiment $\left(\theta_{c 0}\right)$ of $42.5^{\circ} \pm 2.5^{\circ}$. Then, what are the conditions prone for exhibiting a critical angle equal to the absolute one $\left(\theta_{c}=\theta_{c 0}\right)$ in case of a P1 perturbation? Contrary to the P1 case, in the $\mathrm{P} 2$ case, there is no absolute critical angle and shoreline sand waves can develop for low angles under certain conditions. Then, what are the conditions prone for exhibiting no critical angle (i.e., that instability develops for $\theta=0^{\circ}$ ) in case of $\mathrm{P} 2$ perturbation?

To tackle these questions and quantify the relative importance of the parameters $X_{i}$, first, we compute the critical angle $\theta_{c}$ for every combination $\left(\beta_{s}, A, D_{c}, H_{s}, T_{p}\right)$ (for an example, see Figure $\mathrm{S} 2$ in the supporting information). Cases where the critical wave angles are strictly equal for perturbations $\mathrm{P} 1$ and $\mathrm{P} 2$ represent about $8.32 \%$ of the experiment, in the space $\left(\beta_{s}, A, D_{c}, H_{s}, T_{p}\right)$. Then, we use a logistic regression method [see Hothorn and Everitt, 2014, chap. 7], focusing on the probability $p$ that $\theta_{c}=\theta_{c 0}$ in the P1 case and that $\theta_{c}$ does not exist in the P2 case. The Logit function is defined as $\operatorname{Logit}(p)=\log (p /(1-p))=\log ($ odds ratio $)$ and $\operatorname{Logit}(p)$ is approximated by a linear combination of the parameters, i.e., in the present case $\left(\beta_{s}, A, D_{c}, H_{s}, T_{p}\right)$, such that

$$
\operatorname{Logit}(p)=a_{0}+a_{\beta_{s}} \beta_{s}+a_{A} A+a_{D_{c}} D_{c}+a_{H_{s}} H_{s}+a_{T_{p}} T_{p}
$$

The obtained logistic regression model exhibits a good fit with the data $\left(R^{2} \sim 89 \%\right.$ and $\sim 75 \%$, for the P1 and P2 perturbations, respectively) and a good prediction skill (with an area under the receiver operating characteristic (ROC) curve of $99.6 \%$ and $96.3 \%$, respectively; see Metz [1978] for details on the ROC analysis principle). 
Table 2. Regression Coefficients of the Logistic Regression in Dimensional and Normalized $\left(^{*}\right)$ Space of the Parameters $X_{i}$, for the Perturbation Shapes P1 (Profile Shift) and P2 (Linear Decay of Bed Level Perturbation) ${ }^{\mathrm{a}}$

\begin{tabular}{lccccccc}
$f$ & Coefficient Value & $a_{0}$ & $a_{\beta_{s}}$ & $a_{A}$ & $a_{D_{c}}$ & $a_{H_{s}}$ & $a_{T_{p}}$ \\
\hline P1 & Dimensional & 9.35 & NS & 14.4 & 0.589 & NS & -3.59 \\
& Normalized & -2.8 & NS & 3.6 & 14.8 & NS & -43.1 \\
P3 & Dimensional & -0.32 & 36.02 & -29.46 & 0.25 & -0.62 & NS \\
& Normalized & -0.94 & 17.65 & -7.37 & 6.40 & -2.32 & NS \\
\hline
\end{tabular}

aThe normalized space corresponds to $X_{i}$ parameters scaled between 0 and 1. "NS" refers to nonsignificant effect.

First, the logistic regression coefficients (Table 2) show that $p\left(\theta_{c}=\theta_{c 0}, X\right)$ only depends on $A, D_{c}$ and $T_{p}$ in case of a P1 perturbation (consistently with the results of the previous subsections). Figure 7a shows, in the space $\left(A, D_{c}, T_{p}\right)$, the restricted number ( $8 \%$ of the explored combinations $\left.\left(\beta_{s}, A, D_{c}, H_{s}, T_{p}\right)\right)$ of cases where $\theta_{c}=\theta_{c 0}$. In case of a P2 perturbation, the regression coefficients (Table 2 ) show that $p\left(\theta_{c}\right.$ does not exist, $X$ ) only depends on $\beta_{s}, A, D_{c}$, and $H_{s}$ (indeed, $T_{p}$ has a nonsignificant effect as indicated by the high $p$ value of the Wald statistics). The distribution of the configurations of the grid experiment leading to the nonexistence of $\theta_{c 0}$ in the space $\left(\beta_{s}, A, D_{c}, H_{s}\right)$ shows that the number of such configurations is high (Figure $7 \mathrm{~b}$, in black).

Second, the sign of the coefficients (Table 2 ) indicate that for $\mathrm{P} 1, A$ and $D_{c}$ increase the odds ratio for observing the absolute critical angle $\theta_{c 0}$, while $T_{p}$ decreases it. For $\mathrm{P} 2, \beta_{s}$ and $D_{c}$ increase the odds ratio for not observing any critical angle $\theta_{c}$, whereas $A$ and $H_{s}$ decrease these odds, consistently with the results of section 3.2.

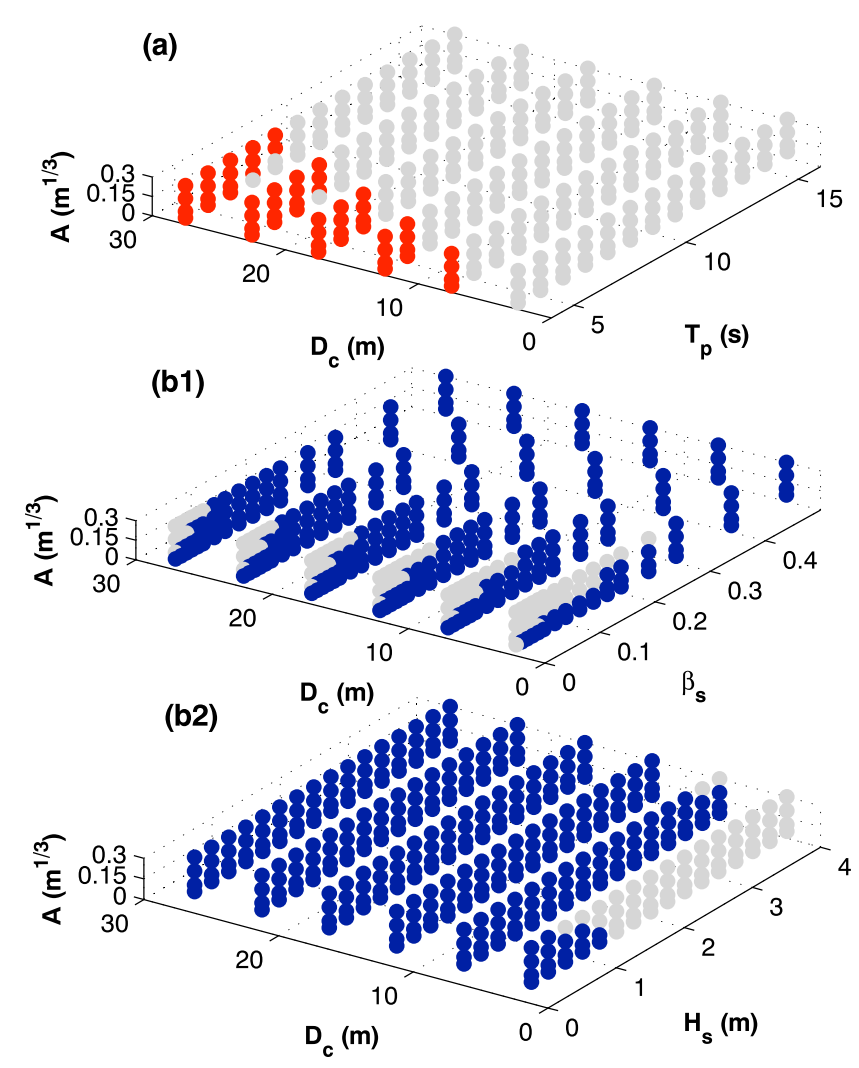

Figure 7. (a) For the $\mathrm{P} 1$ perturbation, grid experiment points (in red) corresponding to the configurations $\left(A, D_{c}, T_{p}\right)$ leading to $\theta_{c}=\theta_{c 0}$. (b1 and b2) For the $\mathrm{P} 2$ perturbation, grid experiment points (in blue) corresponding to the configurations $\left(\beta_{s}, A, D_{c}, H_{s}\right)$ leading to the absence of any $\theta_{c}$. 


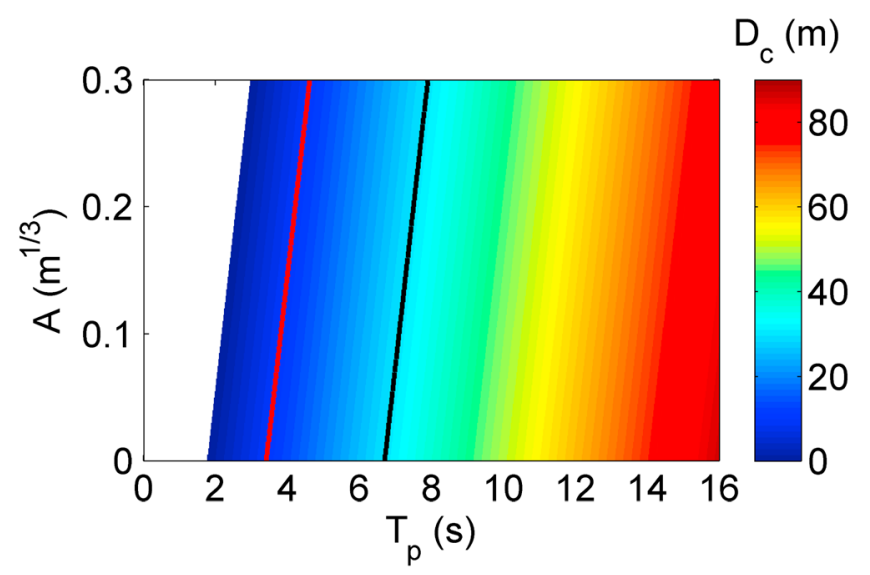

Figure 8. $D_{c}$ at a probability $p\left(\theta_{c}=\theta_{c 0}\right)=0.95$ (equation (12)) plotted in the parameter space $\left(T_{p}, A\right)$. The red and black lines indicate the $10 \mathrm{~m}$ and $30 \mathrm{~m}$ isovalue contours of $D_{c}$, respectively.

Third, one interest of the statistical analysis is that the obtained normalized coefficients (Table 2) allow to rank the effect of the parameters. In case of the P1 perturbation, the relative effect of $T_{p}$ is larger than the one of $D_{c^{\prime}}$ which is much larger than the one of $A$. From the largest to the smallest, we can also rank the parameters for the case of a P2 perturbation: $\beta_{s^{\prime}} A, D_{c^{\prime}} H_{s}$. However, this should not be interpreted as an absolute result as it is sensitive to the range of $X_{i}$ (Table 1). The dimensional coefficients can be used to compute the dimensionless ones when different parameter ranges are considered and thus to rank the contributions for the considered ranges.

Finally, this logistic approach allows to estimate the probability $p$, using the relationship $p=1 /\left(1+e^{- \text {Logit }(p)}\right)$ and equation (11) to compute Logit $(p)$. Then, in a given site, if the parameters (i.e., the vector $X$ ) are known, the probability $p$ can be estimated using the dimensional regression coefficients and thus without requiring any additional model run (see section 4.5 for an example).

For instance, for a P1 perturbation, considering different ranges for $\beta_{s}([0.02, \ldots, 0.1]$ or $[0.02, \ldots, 0.2]), A$ $\left([0.05, \ldots, 0.1]\right.$ or $\left.[0.05, \ldots, 0.2] \mathrm{m}^{1 / 3}\right), D_{c}([5, \ldots, 10]$ or $[5, \ldots, 20] \mathrm{m})$ and assuming $H_{s} \in[0.5, \ldots, 3] \mathrm{m}$ and $T_{p} \in[5, \ldots, 15] \mathrm{s}$, we find that $p\left(\theta_{c}=\theta_{c 0}\right)$ is most of the time equal to 0 , confirming the low probability to observe $\theta_{c}=\theta_{c 0}$. Equation (11) can also be used to identify the sites prone to $\theta_{c}=\theta_{c 0}$ by estimating one of the three significant parameters (e.g., $D_{c}$ ) as a function of the two others (e.g., $A$ and $T_{p}$ ) for a given value of the probability $p$ :

$$
D_{c}=c_{0}+c_{p} \operatorname{Logit}\left(p\left(\theta_{c}=\theta_{c 0}\right)\right)+c_{T_{p}} T_{p}+c_{A} A
$$

with $c_{0}=-a_{0} / a_{D_{c^{\prime}}}, c_{p}=-1 / a_{D_{c^{\prime}}} c_{T_{p}}=-a_{T_{p}} / a_{D_{c^{\prime}}} c_{A}=-a_{A} / a_{D_{c^{\prime}}}$ such that $c_{0}=-15.848 \mathrm{~m}, c_{p}=1.695 \mathrm{~m}$, $c_{T_{p}}=6.085 \mathrm{~m} / \mathrm{s}$, and $c_{A}=-24.407 \mathrm{~m}^{2 / 3}$. A is 1 to 2 orders of magnitude smaller than $T_{p}$, while $c_{T_{p}}$ and $c_{A}$ have similar orders of magnitude. This illustrates the minor effect of $A$, compared to $T_{p}$, as shown in Table 2 . Equation (12) is used to identify the combinations prone to exhibit the absolute critical angle, for instance, with a probability $p\left(\theta_{c}=\theta_{c 0}\right)=0.95$ (Figure 8). Taking into account that large closure depths are not expected to be much larger than about $30 \mathrm{~m}$, sites where the absolute critical angle is likely to be observed should be characterized by wave period smaller than 7-8 s (as shown in Figure 8) and even smaller (e.g., 4 s) when considering smaller closure depths (e.g., $\sim 10 \mathrm{~m}$ ). Thus, if we assume that in nature, perturbations could be of type $\mathrm{P} 1$, there should be a low probability to observe the absolute critical angle $\theta_{c 0}$ and the sites prone to exhibit it would be those characterized by a small wave period and/or a large closure depth. Using equation (12) with a large $p$ value could help identifying such sites and, thus, if $\theta \geq \theta_{c 0}$, sites prone to HAWI.

In the case of $\mathrm{P} 2$ perturbation, considering the same parameter ranges as in the previous paragraph, the probability $p$ that there is no critical angle appears to be quite large, almost never equal to 0 . Depending on the considered ranges, each of the parameters $H_{s^{\prime}} D_{c^{\prime}} A$, or $\beta_{s}$ may be the dominant parameter. If we assume that in nature, perturbations could be of type $\mathrm{P} 2$, then there should be a strong probability to observe shoreline sand waves. 


\section{Discussion}

4.1. Sensitivity to the Bathymetric Perturbation

The instability onset has been investigated for two bathymetric perturbation shapes. The sensitivity of the results to this choice is investigated considering the following additional perturbation shapes:

$$
\begin{gathered}
P 3: f(y)=\frac{1}{\beta_{s}} \frac{\mathrm{d} D_{0}}{\mathrm{~d} y}\left(1-\frac{D_{0}}{D_{c}}\right) \\
P 4: f(y)=1 \text { if } y \leq y_{b}, f(y)=1-\frac{y-y_{b}}{y_{c}-y_{b}} \text { otherwise }
\end{gathered}
$$

First, as stated in [Falqués and Calvete, 2005], strictly speaking, the profile shift perturbation P1 is incompatible with the concept of closure depth since in this case there is a bathymetric perturbation which decays offshore but which extends up to infinity, i.e., beyond the closure depth. As a consequence, the profile shift perturbation has the drawback to present a discontinuity at $y_{c}$. Even if the jump in bed level at $D_{c}$ is small, the depth contours are all parallel to the undulating shoreline until $D_{c}$ and then suddenly straight, which is unrealistic. To address these drawbacks, a second shape function (P3) is considered, characterized by a gradual decrease in the perturbation of the depth contours to straight lines at $D_{c}$ (equation (13)). Second, the 1D-morfo model does not resolve the surf zone, which, in one-line models, collapses into the "shoreline." For this reason, a perturbation that starts to decay already in the surf zone seems questionable. Following this idea, a fourth shape function (P4) is defined such that P4 is equal to 1 in the surf zone and decreases linearly from 1 at the breaking point to 0 at $D=D_{c}$ (equation (14)), as in [Idier et al., 2011].

The probability of instability onset $\left(p_{s}\right)$ obtained with the $\mathrm{P} 3$ and $\mathrm{P} 4$ perturbations (Figure $\mathrm{S} 3$ in the supporting information) exhibits similar patterns as those obtained with the P1 and P2 perturbations, respectively: in case of a P3 perturbation, an absolute critical angle $\theta_{c 0}=47.5^{\circ} \pm 2.5^{\circ}$ is found, whereas for a P4 perturbation, instability cases occur for the entire range of $\theta$ values. This suggests that there are two types of bathymetric perturbations: those where the curvature of the bathymetric contours is always smaller than (or equal to) the shoreline curvature (P1, P3) and those where the curvature can be larger than the shoreline curvature $(\mathrm{P} 2, \mathrm{P} 4)$. The first type leads to the existence of an absolute critical angle $\theta_{c 0}$, while the second type leads to the absence of such absolute critical angle. However, P3 leads to much smaller probabilities ( 2 to 3 times smaller) than P1 but also to a smaller range of parameters leading to instability. Regarding P4, the quantitative results are quite close to the ones obtained considering a P2 perturbation: the areas of instability are the same and the probabilities are only slightly larger, with differences smaller than $10 \%$.

\subsection{Shoreline Sand Wave Wavelength}

The modeling results highlight the key role of the bathymetric perturbation shape on the instability onset. In addition to this information, the 1D-morfo model provides the wavelength of the linearly most amplified mode (LMA) for each investigated configuration (see section 2.3). For both perturbation shapes P1 and P2, the LMA modes exhibit wavelengths ranging from few hundred meters to several tens of kilometers (Figure 9), i.e., correspond to kilometer-scale shoreline sand waves. The main difference is that for a P1 perturbation the quartiles of the wavelengths of the grid experiment decrease with the wave incidence angle, while for a P2 perturbation these statistical moments first increase (until $\theta \simeq 50^{\circ}$ ) and then decrease with $\theta$. In addition, the overall LMA wavelengths are larger for a P1 perturbation, while for very oblique waves $\left(\theta \geq 70^{\circ}\right)$, the wavelengths are of the same order of magnitude $(1 \pm 0.5 \mathrm{~km})$ for both perturbation shapes. Thus, the bathymetric perturbation shape plays a key role not only on the instability onset but also on the wavelength of the associated linearly most amplified mode.

\subsection{Shoreface Slope Effect}

As shown in section 3.1, the overall shoreface slope, characterized by $A$, has a positive effect on the instability in case of $\mathrm{P} 1$ and negative in case of P2. The reasons for this can be investigated by looking at the expression of the complex growth rate provided by Idier et al. [2011, equation (7)]. By examining the $e_{2}$ and the $e_{3}$ terms, related to the perturbation in wave angle and in wave height, respectively, it turns out that only $e_{2}=2 \theta_{b i}^{\prime} / K a$, where $\theta_{b i}^{\prime}$ is the imaginary part of the perturbed wave angle at breaking, exhibits opposite trends when increasing $A$ (we here adapted the expression to the notation and the definition of the amplitude, $a / 2$, in the present paper). It increases (decreases) with $A$ in case of a P1 (P2) perturbation. This term is related to refraction and is always positive as a result of wave rays tending to rotate in the same direction as the bathymetric contours. Thus, for both perturbation shapes, the behavior with respect to $A$ is related to wave refraction. 

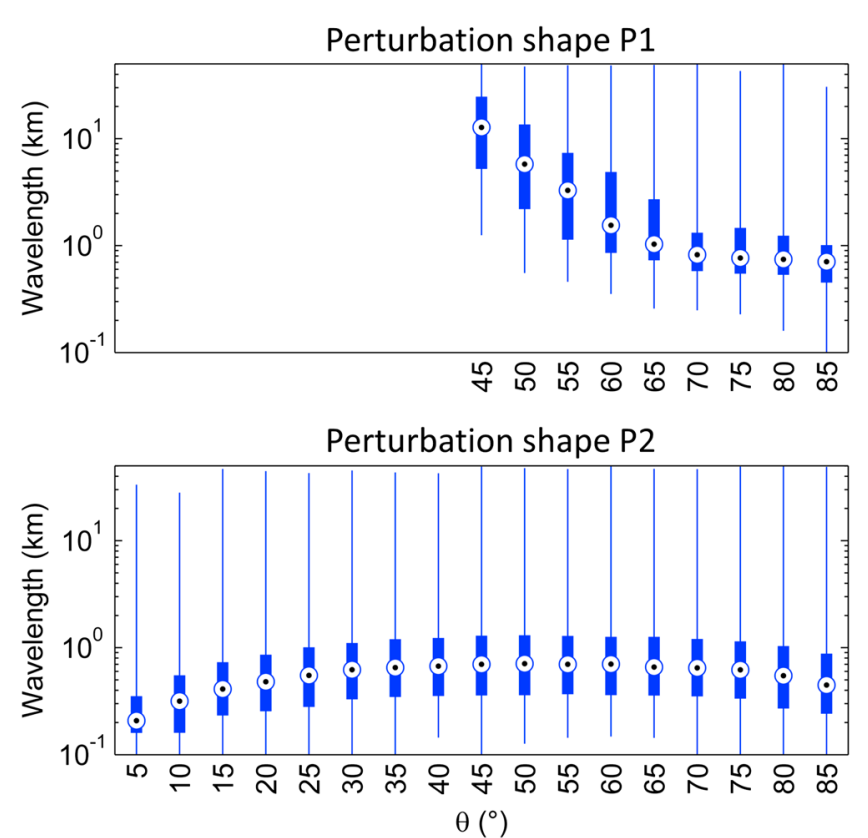

Figure 9. Boxplot of wavelength $L$ of the linearly most amplified modes, for the entire grid experiment, i.e., 55,814 runs per wave direction $\theta$ : median (circle), 0.25 quantile, and 0.75 quantile (vertical bar), and values above the 0.75 and below the 0.25 quantiles (vertical line).

The influence of $A$ and of the shape of the bathymetric perturbation on wave refraction (here on the $\theta_{i}^{\prime}$ variable) can be understood by focusing on normal wave incidence and looking at equation (A3) in Falqués and Calvete [2005]. Taking the water depth, $D=D_{0}(y)$, as independent variable, this equation can be cast into

$$
\frac{\mathrm{d}}{\mathrm{d} D}\left(k_{0}(D) \theta_{i}^{\prime}(D)\right)=-K \frac{\Phi(D)}{\beta(D)} \hat{h}(D)
$$

where $\beta(D)=\mathrm{d} D_{0}(y) / \mathrm{d} y, k_{0}(D)$ is the wave number of the water waves, $\Phi(D)$ collects various functions of $D$ defined from linear water wave theory, and $\hat{h}(D)=a \beta_{s} f(D) / 2$. Notice that this equation is linear, with homogeneous boundary condition, $\theta_{i}^{\prime}\left(D_{c}\right)=0$. Therefore, if the forcing term is multiplied by a constant, the solution $\theta_{i}^{\prime}(D)$ will be the same but multiplied by this constant.

In case of a $\mathrm{P} 2$ perturbation, $\hat{h}(D)$ does not depend on $A$ since it cancels out from the ratio $y / y_{c}$ in equation (6). On the other hand, $\beta(D)$ is proportional to $A^{3 / 2}$ for each $D$. Then, the dependence on $A$ is only present in the forcing term through $\beta(D)$ and therefore, the solution $\theta_{i}^{\prime}(D)$ decreases by increasing $A$, and so $\theta_{b i}^{\prime}(D)=\theta_{i}^{\prime}\left(D_{b}\right)$. Therefore, the instability is favored by decreasing $A$.

In case of a P1 perturbation, $\hat{h}(D)=a \beta(D) / 2$, so that the forcing term does not depend on $A$ with the result that $\theta_{b i}^{\prime}(D)$ does not depend on $A$ either. Thus, the instability should be insensitive to $A$. In the case of oblique wave incidence, another term appears in equation (A3) of Falqués and Calvete [2005]. The analysis in this case is not simple, but it turns out that the additional term makes $\theta_{b i}^{\prime}(D)$ increase with $A$, i.e., that instability is favored by large $A$.

\subsection{Bed Perturbation in Nature?}

To find out whether these types of perturbation shape do represent sand wave bathymetry, we should analyze bathymetric data in coastal areas exhibiting shoreline sand waves. However, we face two difficulties: (1) detailed observations of self-organized sand waves are scarce, and this is even worse regarding the bathymetry associated with the sand waves and (2) when sand waves are observable they can hardly be considered in the early stage of formation for linear stability analysis to be applicable. As a first attempt to characterize the curvature of perturbation shape from real cases in nature, we analyze three shoreline sand wave sites where processed bathymetric data are available (Figure 10): Holmslands Tange [Kaergaard et al., 2012] and the distal end and tow of the Long Point spit of Lake Erie [Davidson-Arnott and van Heyningen, 2003]. 

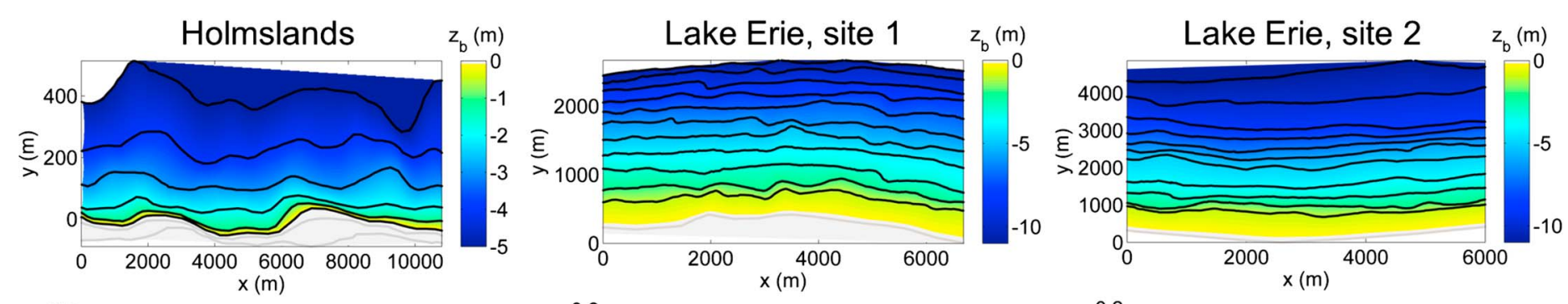

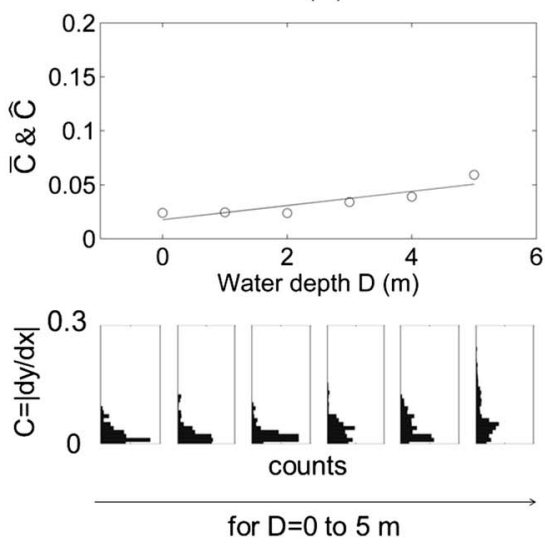

(a)
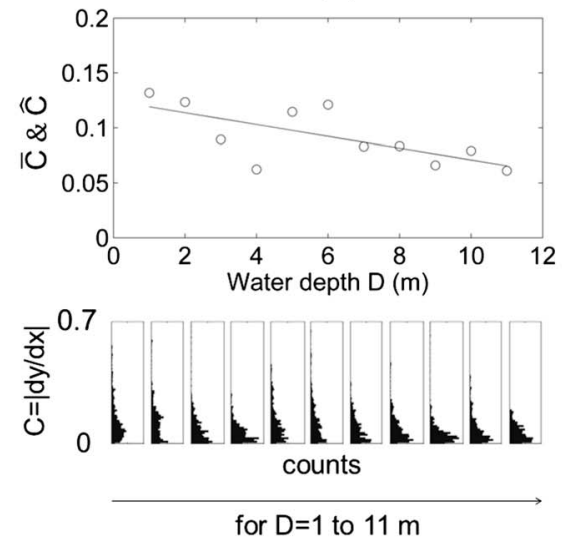

(b)
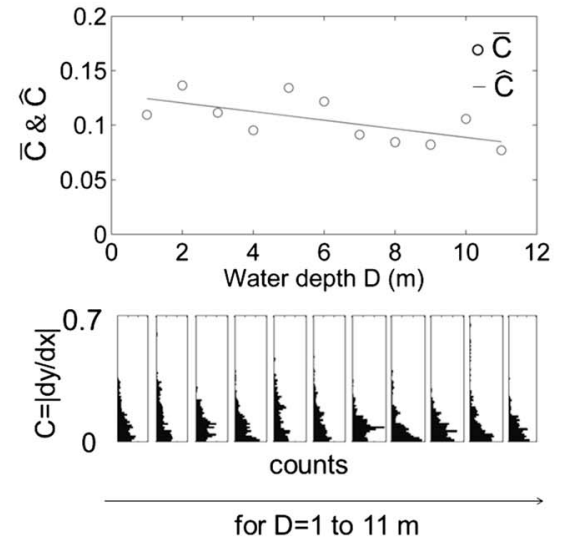

(c)

Figure 10. Bed level contours, bathymetric curvature indicators $(\bar{C}, \hat{C})$, and distribution of horizontal slope of depth contours $(C(D, x)=|\mathrm{d} y / \mathrm{d} x|)$ versus the water depth for (a) the Holmslands site, (b) the distal end, and (c) the toe of the Lake Erie Long Point spit. Depth contours are plotted every meter. The black contours are used in the curvature analysis. For the Holmsland Tange site, the depth contours have been digitized in Figure 12 of Kaergaard et al. [2012]. For the Long Point sites, the contours come from the NOAA database. The colored surface has been obtained by interpolation (natural neighbor method) of the plotted bathymetric contours. In the white area, the natural neighbor provides no bathymetric value. $C(D, x)$ is computed along each bathymetric contour of depth $D$ and every $5 \mathrm{~m}$ in the $x$ direction. $\bar{C}(D)$ is the mean of $C(D, x)$ for the depth $D$, i.e., $\bar{C}(D)=\left(1 / n_{x}\right) \sum_{i=1}^{n_{x}} C\left(D, x_{i}\right)$. $\hat{C}(D)$ is obtained by linear regression of $C(D, x)$.

The Holmslands Tange site is characterized by sand waves of small amplitude ( $a / L=0.008$, with $L=5 \mathrm{~km}$ ). We use the filtered isobathymetric lines digitized from [Kaergaard et al., 2012] (Figure 12 herein, where the bars have been removed). The depth contours stop at $5 \mathrm{~m}$ depth (Figure 10a). However, Kaergaard et al. [2012] and Falqués et al. [2017] suggest that $D_{c}$ could be substantially larger than $5 \mathrm{~m}$.

The Long Point sand waves are characterized by larger relative amplitudes $[a / L=0.1$, with $L \sim 1 \mathrm{~km}$, after Davidson-Arnott and van Heyningen, 2003]. We use the bathymetric contours provided by NOAA (data available at http://www.ngdc.noaa.gov/mgg/greatlakes/erie.html) (Figures 10b and 10c). These contours do not include the shoreline $D=0 \mathrm{~m}$. Thus, the analysis focuses on the depth contours $D=1 \mathrm{~m}$ to $D=D_{c}$, with $D_{c} \sim 11 \mathrm{~m}$ (see section 4.5 for the estimation of $D_{c}$ ).

To avoid any effect of small features (e.g., sandbars) or larger features (e.g., the spit related curvature), small and large wavelengths are filtered out from the bathymetric contours (for Holmslands Tange, $L<200 \mathrm{~m}$ and $L>7000 \mathrm{~m}$ are filtered out; for the Long Point site, $L<200 \mathrm{~m}$ and $L>2000 \mathrm{~m}$ are filtered out). Then, we compute $C(D, x)=|\mathrm{d} y / \mathrm{d} x|$ along each depth contour. As the depth contours are undulating, for a given wavelength, the mean $(\bar{C}(D))$ of $C(D, x)$ and the linear regression prediction $\hat{C}(D)$ (obtained by minimizing the least mean square error over the entire data set) can be considered as indicators of the maximum curvature associated with a water depth $D$. Both indicators are increasing (decreasing) in the offshore direction for Holmslands Tange (Long Point sites) (Figure 10).

Thus, the observed bathymetry at Holmslands Tange supports the essential curvature characteristics of a perturbation of type P2, i.e., a maximum curvature of the bathymetric lines away from the shoreline. This suggests that the type of bathymetric perturbation observed on this site is prone to instability even for wave incidence angles smaller than $\simeq 42^{\circ}$. At Long Point, the observed bathymetry would support the curvature characteristics of the $\mathrm{P} 1$ or $\mathrm{P} 3$ type, suggesting that this site is not prone to LAWI but prone to the existence of an absolute critical angle. This is one reason for observing $\theta_{c} \simeq 42^{\circ}$ on this site (as in Ashton and Murray [2006b]). 
In this analysis, we assumed that (1) in the chosen wavelength range (e.g., $200 \mathrm{~m}$ to $2000 \mathrm{~m}$ for the Long Point sites), all the dominant bed forms are related to sand waves, (2) the shoreline sand waves have a small enough amplitude for assuming that sand waves are at their initiation stage (this could be the case for Holmslands with $a / L=0.008$, while this is not the case at Long Point spit with $a / L \sim 0.1$ ). Both assumptions are debatable. However, it is still remarkable to observe that both cases could happen in shoreline sand waves area: increase or decrease of depth contour curvature in the offshore direction. Further systematic investigations on other sand wave sites are necessary to confirm this preliminary analysis, but they require detailed bathymetric data which are still lacking in such areas.

As a preliminary analysis, it seems that several factors could favor bathymetric anomalies supporting the essential curvature characteristics of a perturbation of type P2. First, it is worthwhile to notice that offshore tidal and current sand waves have been observed off the Holmsland coast, at depths ranging from 8 to $18 \mathrm{~m}$ [Anthony and Leth, 2002]. Second, after the study of Limber et al. [2017] on the Rodanthe shoreline (U.S.), shoals could trigger the development of shoreline sand wave under waves of low incidence angle. On the Rodanthe site, as a consequence of the shoal, the depth contours reach a maximum curvature larger than the one of the shoreline. This effect of shoal on shoreline sand wave development under low incidence angle is consistent with the theoretical work of Idier et al. [2011]. Thus, there are indications that offshore morphodynamic and/or geological features could favor perturbations of type P2. However, further investigations are required to better understand which conditions favor which perturbation.

\subsection{Critical Angle for HAWI}

All modeling studies [Ashton et al., 2001; Falqués and Calvete, 2005; Ashton and Murray, 2006a; van den Berg et al., 2012; Kaergaard and Fredsoe, 2013a] with the exception of Idier et al. [2011] have found the existence of a critical angle for $\mathrm{HAWI}$, and, indeed, observations suggest that high-angle wave climates correlate with sand waves existence [Ashton et al., 2001; Ashton and Murray, 2006b; Medellín et al., 2009; Idier and Falqués, 2014; Kaergaard and Fredsoe, 2013b]. However, to our best knowledge, the value of the critical angle has only been tested in the spit of Long Point (Lake Erie, Canada) by Ashton and Murray [2006b]. This site is characterized by a coastal stretch without sand waves in between two stretches with sand waves. The overall shoreline orientation is changing such that under the same deep water wave angles, the incidence angles relative to the local shoreline exhibit spatial differences of about $25^{\circ}$. In addition, section 4.4 suggests that the bathymetric perturbation is prone to the existence of an absolute critical angle. Ashton and Murray [2006b] defined a dimensionless "instability index," $\Gamma$, which assesses the competition between diffusion and antidiffusion for a wave climate. This index depends on deep water wave height, period, and direction and is based on the underlying assumption that the bathymetric contours are parallel to the shoreline, i.e., our P1 perturbation. When using the CERC formula, this index is antidiffusive $(\Gamma<0)$ if the weighted proportion of angles $\theta$ larger than $42^{\circ}$ is higher than those smaller than $42^{\circ}$. In other words, it is based on the absolute critical wave angle $\theta_{c 0}$ but not on the critical wave angle which also depends on $D_{c}, A$, or $T_{p}$ (in case of a P1 perturbation). Ashton and Murray [2006b] computed the local instability index along the spit, and they found a good correlation with the existence or not of sand waves, i.e., sand waves show up when $\Gamma<0$ and they are not present when $\Gamma>0$. This is a clear indication that sand waves form on that coast whenever deep water waves approach at angles greater than about $42^{\circ}$ with respect to the shoreline.

Such value nearly equals the absolute critical angle $\theta_{c 0}$ that we obtain for the P1 perturbation and using also the CERC formula. To assess the probability that the critical wave angle for Long Point spit coincides with the absolute critical angle, we use the probability function $p\left(\theta_{c}=\theta_{c 0}\right)$ introduced in section 3.3. This function depends on $A, D_{c}$, and $T_{p}$. To estimate $D_{c}$ and $T_{p}$, we use the wave hindcast [Hubert, 1992] of the Wave Information Studies (WIS) of the U.S. Army Corps of Engineers (USACE) (data available at http://wis.usace.army. $\mathrm{mil} /)$. The analysis of the time series of hourly wave conditions at the station $92193\left(42.48^{\circ} \mathrm{N},-80.32^{\circ} \mathrm{E}, 20 \mathrm{~m}\right.$ depth) over the period 1979-2014 provides a mean peak period of $3.7 \mathrm{~s}$ and a closure depth of $11.2 \mathrm{~m}$ using the formula of Hallermeier [1978]. It should be recalled that Lake Erie is very elongated such that the fetch at Long Point spit can be larger than $200 \mathrm{~km}$. This explains the large obtained closure depth, together with a small mean peak wave period. For the estimation of $A$, we use the same bathymetric data as in section 4.4 and found values in the range $0.06-0.08 \mathrm{~m}^{1 / 3}$. With these values, a high probability, $p\left(\theta_{c}=\theta_{c 0}\right)=0.97$, is obtained, suggesting $\theta_{c} \approx \theta_{c 0}$ on Long Point spit. The wave climate being not steady, $p\left(\theta=\theta_{c 0}\right)$ is computed also at each time step of the wave time series, and a probability $p\left(\theta=\theta_{c 0}\right)>0.9$ during $70 \%$ of the time is obtained (meaning that $\theta_{c} \approx \theta_{c 0}$ most of the time on Long Point spit). This would explain why 
Ashton and Murray [2006b] found a good spatial correlation between their instability index and the sand wave occurrence on this site.

In general, our grid experiment and the analysis of the results (see section 3.3) show that the probability to be in a configuration such that $\theta_{c}=\theta_{c 0}$ is small when considering the range of all possible parameter values and that observing $\theta_{c 0}$ (e.g., with a 0.95 probability, Figure 8 ) requires very specific conditions (small wave period and large closure depth). The initial purpose of the instability index developed by Ashton and Murray [2006a] was to provide general guidance rather than exact conditions for predicting shoreline stability/instability. However, the above analysis highlights that under certain conditions, this index should be more than a general guide: when negative, the index appears as a necessary (but not sufficient) condition for shoreline instability but converge to sufficient condition for small wave period and/or large closure depth. This comment holds for a bathymetric perturbation corresponding to a profile shift (P1).

\section{Conclusions}

A systematic model exploration of the relative contribution of wave conditions, shoreface shape, and closure depth to self-organized shoreline sand wave generation is presented. Since the analysis is based on the one-line approximation, a shape for the bathymetry associated with the sand waves must be defined and the sensitivity to this shape is investigated. Two perturbation shapes are considered: one defined from a shift in the cross-shore equilibrium bathymetric profile and the other one defined from a linear seaward decay in bed level perturbation. Importantly, these definitions imply that the curvature of the depth contours cannot be larger than the one of the shoreline in the former case, whereas it can be larger in the latter case if $A^{3} / D_{c} \beta_{s}^{2}<1.48$ (assuming a Dean profile), i.e., if the shoreface slope is small enough and the closure depth and surf zone large enough.

As a consequence of these curvature properties, the critical wave angle for instability is highly sensitive to the shape of the perturbation. For a given profile shift perturbation, there is an absolute critical angle, $\theta_{c 0} \approx 40-50^{\circ}$, below which there is no instability for any condition (HAWI). Observing the absolute critical angle should be exceptional: the Long Point site is one example illustrating the required specific conditions (high-angle waves, small wave period, and large closure depth). A bed level perturbation linearly decreasing in the offshore direction does not exhibit any absolute critical angle, such that, depending on the physical parameters, the critical angle can span the whole range $0 \leq \theta_{c} \leq 90^{\circ}$ and instability can develop also for relatively low angles (LAWI). This is related to the amplitude of the bathymetric undulations being larger than that of the shoreline. The effect of two other perturbation shapes on the instability onset has also been analyzed, confirming that the bathymetric perturbation and the related curvature of the depth contours play a key role in the instability onset, especially for low angles. In fact, the bed perturbation could be classified into two types: those with depth contour curvatures smaller than or equal to the shoreline one and those with depth contour curvature that can be larger than the shoreline one offshore the breaking zone. The analysis of three shoreline sand wave sites suggests that both could exist in nature. This key effect, for the first time identified, explains some differences in the results of previous studies.

The main results of the exploration of the physical parameters are summarized in Table 3. Interestingly, some properties of shoreline instability are insensitive to the shape of the bathymetric perturbation: (1) the wave angle $\theta$ is the dominant parameter for the instability onset, (2) large $D_{c}$ favors instability and reduces the critical wave angle $\theta_{c^{\prime}}$ (3) the effect of $T_{p}$ mainly increases with $\theta_{,}$(4) small $T_{p}$ favors instability and decreases $\theta_{c^{\prime}}$ and (5) $D_{c}$ and $T_{p}$ have the largest effect on $\theta_{c}$ value. The most striking difference is the effect of the cross-shore profile which depends on the perturbation shape: while perturbations of type "profile shift" show little sensitivity to it, bed level perturbations linearly decreasing are highly sensitive to surf zone mean slope and bathymetric gradient, with large $\beta_{s}$ and small $A$ favoring instability.

The analysis presented in this present paper provide quantitative elements which could help to identify sites prone to shoreline sand waves (at least in areas of low variability in the wave climate). In any case and thinking on future field work, the coasts the most prone to shoreline sand waves are those characterized by high-angle waves, large closure depth, and small wave periods. For relatively low angles, additional conditions for instability are a small enough bathymetric gradient of the shoreface and a large enough surf zone slope. For field studies, as the bathymetric anomaly associated with the sand waves has a significant effect on the critical angle, it will be essential to analyze the existing bathymetric data (or undertake surveys), from the coast to the closure depth. 
Table 3. Results Synthesis for the $P 1$ and $P 2$ Perturbation Shapes in Terms of Probability of Shoreline Development $\left(p_{s}\right)$, Relative Effect of the Physical Parameters Versus the Wave Angle $\left(R_{X}\right)$, Probability That the Critical Angle Is Either Equal to the Absolute Critical Angle $p\left(\theta_{c}=\theta_{c 0}\right)$ or Does Not Exist $\left(p\left(\theta_{c} \nexists\right)\right)$, and the Critical Angle Itself ${ }^{a}$

\begin{tabular}{cccccccc}
$f$ & Indicator & $\theta$ & $\beta_{s}$ & $A$ & $D_{c}$ & $H_{s}$ & $T_{p}$ \\
\hline P1 & $p_{s}$ & $\pm^{\mathrm{b}}$ & $=$ & + & $\pm^{\mathrm{b}}$ & $\equiv$ & $\pm^{\mathrm{b}}$ \\
& $R_{X}$ & N.C. & $|\rightarrow|$ & $|\nearrow|$ & $|\nearrow|$ & $|\rightarrow|$ & $|\nearrow|$ \\
& $p\left(\theta_{c}=\theta_{c 0}\right)$ & N.C. & $=$ & + & $\pm^{\mathrm{b}}$ & $=$ & $-^{\mathrm{b}}$ \\
& $\theta_{c}$ & N.C. & $=$ & - & $\pm^{\mathrm{b}}$ & $=$ & $\pm^{\mathrm{b}}$ \\
$\mathrm{P} 2$ & $p_{s}$ & $\pm^{\mathrm{b}}$ & $+^{\mathrm{b}}$ & - & $\pm^{\mathrm{b}}$ & $=$ & $\bar{\Xi}$ \\
& $R_{X}$ & N.C. & $|\searrow|$ & $|\searrow|$ & $|\searrow|$ & $|\searrow|$ & $|\overline{\mid}|$ \\
& $p\left(\theta_{c} \nexists\right)$ & N.C. & $+^{\mathrm{b}}$ & $-{ }^{\mathrm{b}}$ & $\pm^{\mathrm{b}}$ & - & $=$ \\
& $\theta_{c}$ & N.C. & - & + & $\pm^{\mathrm{b}}$ & + & $\pm^{\mathrm{b}}$ \\
\hline
\end{tabular}

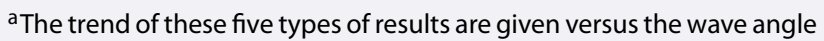
$\theta$, the surf zone slope $\beta_{s}$, the shoreface slope coefficient $A$, the closure depth $D_{c}$, the wave height $H_{s}$, and wave period $T_{p}$. The plus, equal, and minus symbols mean positive effect, no effect, and negative effect, respectively. N.C., "Not Concerned." The underlined cells are cells showing similar conclusion for both the $\mathrm{P} 1$ and $\mathrm{P} 2$ perturbations.

bominant parameters.

\section{Notation}

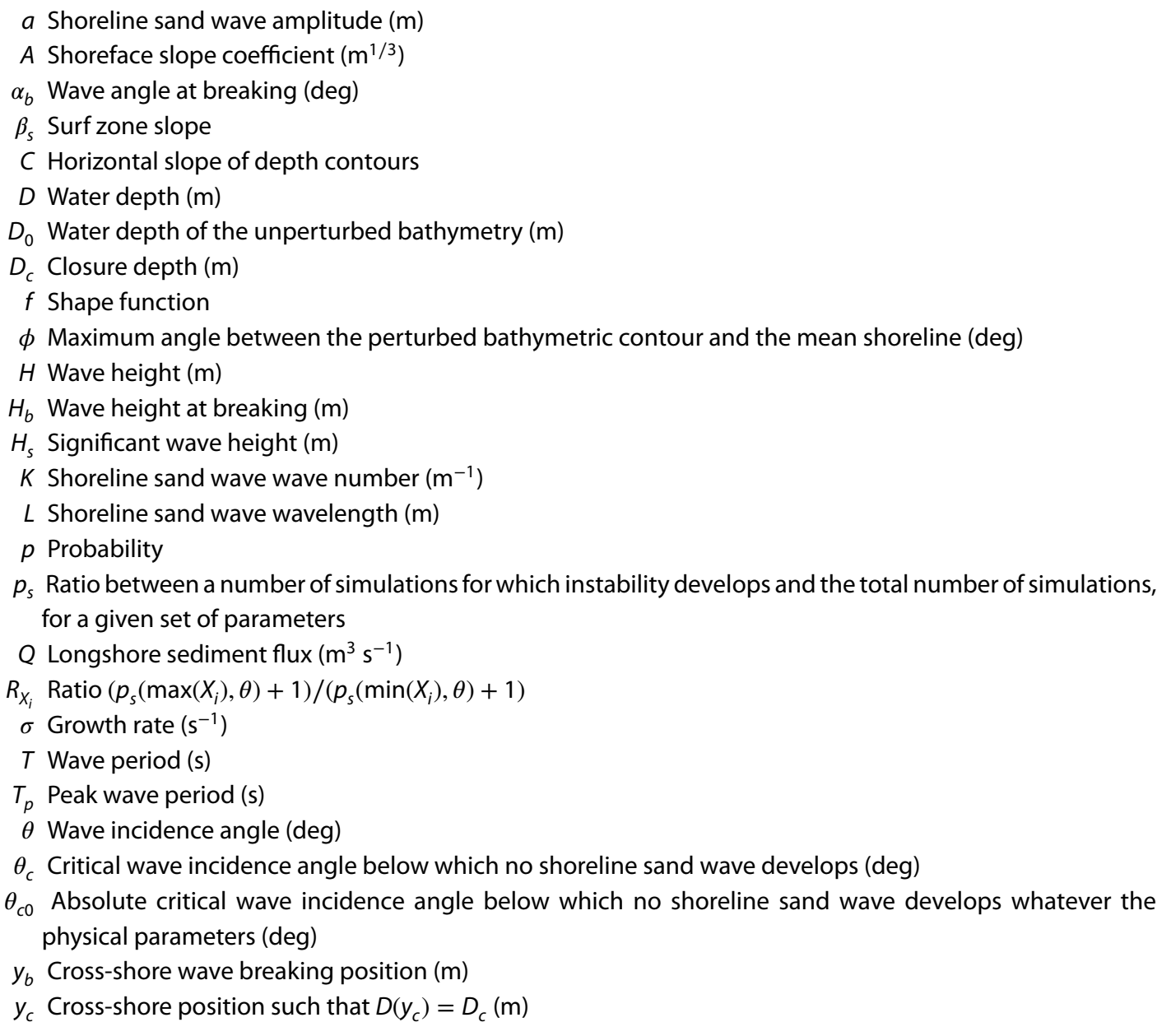




\section{Acknowledgments}

Funding from BRGM (ShorelineSW project) and the Spanish Government (CTM2009-11892/IMNOBE and CTM2015-66225-C2-1/MUSA projects) are acknowledged. These projects have been cofunded by the E.U. (FEDER). The authors are grateful to F. Ardhuin, NOAA, and USACE for providing, respectively, the global wave hindcast data (available at $\mathrm{ftp} / / / \mathrm{ftp}$.ffremer.fr/ffremer/ww3/ HINDCAST/GLOBAL/), the Lake Erie bathymetric contours (available at http://www.ngdc.noaa.gov/mgg/ greatlakes/erie.html), and the Lake Erie wave hindcast data (available at http://wis.usace.army.mil/). The authors like also to thank D. Calvete for interesting discussions and technical support, B. Murray for a fruitful debate that has motivated the analysis of the bathymetric perturbation shape and F. Ribas for discussion on the Holsmlands Tange bathymetric anomaly. The referees are also gratefully acknowledged for their thorough review and useful advices. $y_{m}$ Cross-shore location of the maximum bathymetric curvature $(\mathrm{m})$

$y_{s}$ Cross-shore position of the shoreline $(\mathrm{m})$

$z_{b}$ Seabed level $(\mathrm{m})$

\section{References}

Anthony, D., and J. O. Leth (2002), Large-scale bedforms, sediment distribution and sand mobility in the eastern North Sea of the Danish west coast, Mar. Geol., 182, 247-263.

Ashton, A., and A. B. Murray (2006a), High-angle wave instability and emergent shoreline shapes: 1. Modeling of sand waves, flying spits, and capes, J. Geophys. Res., 111, F04011, doi:10.1029/2005JF000422.

Ashton, A., and A. B. Murray (2006b), High-angle wave instability and emergent shoreline shapes: 2. Wave climate analysis and comparisons to nature, J. Geophys. Res., 111, F04012, doi:10.1029/2005JF000423.

Ashton, A., A. B. Murray, and O. Arnault (2001), Formation of coastline features by large-scale instabilities induced by high-angle waves, Nature, 414, 296-300.

Bender, C. J., and R. G. Dean (2003), Wave field modification by bathymetric anomalies and resulting shoreline changes: A review with recent results, Coast. Eng., 49, 125-153.

Coco, G., and A. B. Murray (2007), Patterns in the sand: From forcing templates to self-organization, Geomorphology, 91, 271-290.

Davidson-Arnott, R. G. D., and A. van Heyningen (2003), Migration and sedimentology of longshore sandwaves, Long Point, Lake Erie, Canada, Sedimentology, 50, 1123-1137.

Dean, R. G. (1977), Equilibrium beach profiles: U.S. Atlantic and Gulf coasts, Tech. Rep., Del. Univ.

Dean, R. G. (1987), Coastal sediment processes: Toward engineering solutions, in Proceedings Coastal Sediments '87, pp. 1-24, Am. Soc. of Civ. Eng., New York.

Falqués, A. (2006), Wave driven alongshore sediment transport and stability of the Dutch coastline, Coastal Eng., 53, 243-254.

Falqués, A., and D. Calvete (2005), Large scale dynamics of sandy coastlines. Diffusivity and instability, J. Geophys. Res., 110, C03007, doi:10.1029/2004JC002587.

Falqués, A., F. Ribas, D. Idier, and J. Arriaga (2017), Formation mechanisms for self-organized kilometer-scale shoreline sand waves, J. Geophys. Res. Earth Surf., 122, 1121-1138, doi:10.1002/2016JF003964.

Hallermeier, L. (1981), A profile zonation for seasonal sand beaches from wave climate, Coastal Eng., 4(3), 253-277.

Hallermeier, R. J. (1978), Uses for a calculated limit depth to beach erosion, in Proceedings 16th Coastal Engineering Conference, Coastal Eng. 1978, pp. 1493-1512, Am. Soc. of Civ. Eng., New York.

Hothorn, T., and B. Everitt (2014), A Handbook of Statistical Analyses Using R, 3rd ed., CRC Press, New York.

Hubert, J. M. (1992), User's guide to the Wave Information Studies (WIS) wave model: Version 2.0, Tech. Rep. WIS Report 27, U.S. Army Corps of Eng., Springfield, Va.

Idier, D., and A. Falqués (2014), How kilometric sandy shoreline undulations correlate with wave and morphology characteristics: Preliminary analysis on the Atlantic coast of Africa, Adv. Geosci., 39, 55-60, doi:10.5194/adgeo-39-55-2014.

Idier, D., A. Falqués, B. G. Ruessink, and R. Garnier (2011), Shoreline instability under low-angle wave incidence, J. Geophys. Res., 116, F04031, doi:10.1029/2010JF001894.

Kaergaard, K., and J. Fredsoe (2013a), Numerical modeling of shoreline undulations part 1: Constant wave climate, Coastal Eng., 75, 64-76.

Kaergaard, K., and J. Fredsoe (2013b), Numerical modeling of shoreline undulations part 2: Varying wave climate and comparison with observations, Coastal Eng., 75, 77-90.

Kaergaard, K., J. Fredsoe, and S. B. Knudsen (2012), Coastline undulations on the West Coast of Denmark: Offshore extent, relation to breaker bars and transported sediment volume, Coastal Eng., 60, 109-122.

Komar, P. D. (1998), Beach Processes and Sedimentation, 2nd ed., Prentice Hall, Englewood Cliffs, N. J.

Limber, P. W., P. N. Adams, and A. B. Murray (2017), Modeling large-scale shoreline change caused by complex bathymetry in low-angle wave climates, Mar. Geol., 383, 55-64, doi:10.1016/j.margeo.2016.11.006.

Medellín, G., R. Medina, A. Falqués, and M. González (2008), Coastline sand waves on a low-energy beach at 'El Puntal' spit, Spain, Mar. Geol., $250,143-156$

Medellín, G., A. Falqués, R. Medina, and M. González (2009), Sand waves on a low-energy beach at 'El Puntal' spit, Spain: Linear Stability Analysis, J. Geophys. Res., 114, C03022, doi:10.1029/2007JC004426.

Mei, C. C. (1989), The Applied Dynamics of Ocean Surface Waves, Advanced Series on Ocean Engineering, vol. 1, World Sci., Singapore.

Metz, C. (1978), Basic principles of ROC analysis, Semin. Nucl. Med., 8(4), 283-298.

Pierson, W. J., and L. Moskowitz (1964), A proposed spectral form for fully developed wind seas based on the similarity theory of S. A. Kitaigorodskii, J. Geophys. Res., 69, 5181-5190.

Rascle, N., and F. Ardhuin (2013), A global wave parameter database for geophysical applications. Part 2: Model validation with improved source term parameterization, Ocean Model., 70(10), 174-188, doi:10.1016/j.ocemod.2012.12.001.

Ribas, F., A. Falqués, H. E. de Swart, N. Dodd, R. Garnier, and D. Calvete (2015), Understanding coastal morphodynamic patterns from depth-averaged sediment concentration, Rev. Geophys., 53, 362-410, doi:10.1002/2014RG000457.

Riggs, S. R., W. J. Cleary, and S. W. Snyder (1995), Influence of inherited geologic framework on barrier shoreface morphology and dynamics, Mar. Geol., 126(1), 213-234.

Ruessink, B. G., and M. C. J. L. Jeuken (2002), Dunefoot dynamics along the Dutch coast, Earth Surf. Process. Landforms, 27, $1043-1056$.

Ryabchuk, D., I. Leont'yev, A. Sergeev, E. Nesterova, L. Sukhacheva, and V. Zhamoida (2011), The morphology of sand spits and the genesis of longshore sand waves on the coast of the eastern Gulf of Finland, Baltica, 24(1), 13-24.

Uguccioni, L., R. Deigaard, and J. Fredsoe (2006), Instability of a coastline with very oblique wave incidence, in Proceedings of the 30th International Conference Coastal Engineering, pp. 3542-3553, World Sci., ASCE, Hackensack, N. J.

Valvo, L. M., A. B. Murray, and A. Ashton (2006), How does underlaying geology affect shoreline change? An initial model investigation, J. Geophys. Res., 111, F02025, doi:10.1029/2005JF000340.

van den Berg, N., A. Falqués, and F. Ribas (2012), Modelling large scale shoreline sand waves under oblique wave incidence, J. Geophys. Res. 117, F03019, doi:10.1029/2011JF002177.

Wright, L. D., and A. D. Short (1984), Morphodynamic variability of surf zones and beaches: A synthesis, Mar. Geol., 56, 93-118. 